\title{
ENSAYO SOBRE LOS PLANOS DE LA CIUDAD DE VERACRUZ
}

POR

MANUEL TOUSSAIN T

I A ciudad de la Nueva Veracruz, establecida en su actual emplazamiento por el Conde de Monterrey el año de 1599, es una de las más importantes en la historia de la Colonia.

De las diversas poblaciones que tuvieron antes el mismo nombre, la primera fué indudablemente el primer núcleo poblado que se estableció en lo que hoy es México. Existió alli mismo el primer ayuntamiento del país o sea la primera autoridad civil de la Nueva España. Probablemente estuvo en el sitio que ocupa la actual ciudad, llamado Chalchiucuhecan.

Poco tiempo después la ciưad fué cambiada más al norte, al sitio conocido con el nombre de Quiahuiztla, donde duró algunos años, para ser establecida definitivamente por 1523 o 24 , a orillas del río de Veracruz que hoy se conoce con el nombre de Río de la Antigua. Poco se conoce acerca de esta antiquísima ciudad y sólo los documentos publicados por el señor Troncoso en sus papeles de Nueva España y la Relación manus- 
crita de Diosdado que existe en la Biblioteca Nacional pueden ilustrarnos acerca de ella. 1

Pero la necesidad de cambiarla al sitio actual era evidente: todos los navios que llegaban de Europa fondeaban junto al arrecife de San Juan de Ulúa ; existió alli desde tempranos tiempos una fortaleza que en el transcurso de los siglos fué perfeccionándose; de allí había que llevar las mercancías a la Antigua Veracruz o directamente a la ciudad de México, por lo que resultaban varios inconvenientes que se solucionaron con la fundación de la nueva ciudad. El proyecto era bastante antiguo: ya desde 1590 cuando pasó por la localidad Bautista Antonelli formuló un proyecto de población, enfrente de la isla de Ulúa, en el lugar en que se encontraban las llamadas Ventas de Buitrón. Es éste, pues, el primer plano de la ciudad de Veracruz hecho aún antes de fundarla. Es de notar que hay dos versiones del plano, una firmada por Antonelli, que es la que reproducimos tomándola de las fotocopias que hizo Troncoso, y otra que cita Torres Lanzas firmada por el capitán Pedro Ochoa de Leguizamo. ${ }^{2}$

Aparece la ciudad en la forma habitual del trazado para poblaciones coloniales: una plaza rectangular alrededor de la cual se encuentran los edificios públicos, la iglesia, etc. Las manzanas forman calles que corren sensiblemente de Norte a Sur y de Este a Poniente, con una ligera inclinación pues aparecen paraleras a la costa. En el plano de Antonelli hay una pequeña relación que indica que el lugar es sano por no encontrarse terrenos pantanosos. Es indudable que desde esta fecha existió el proyecto del traslado de la ciudad que al fin fué llevado a cabo por el Conde de Monterrey. (Fig. 1)

Un grupo de planos que deben citarse porque aunque se refieren a Ulúa, la historia de la fortificación está íntimanıente ligada con la de la ciudad, se encuentra en el Archivo de Indias y han sido estudiados magistralmente por don Diego Angulo en su Discurso de Recepción de la Academia de la Historia. ${ }^{3}$ Fundamentalmente se trata de cuatro planos

1 Acaso refiérese a la ciudad el plano que registra Orozco y Berra en su carto. grafía (No. 1362) y describe así: "Veractuz M8. es copia, más que de un plano de ana vista de Veracruz antez que el puerto que existio en la Antigua se pasara al lugar actual, el original corresponde pues al siglo XVI pertenece al señor José Fernández Ramírez y forma parte de un portulano manuscrito con notas acerca de los texritorios $y$ de las navegaciones, obra de alguno de los pilotos de entonces."

2 Angulo le llama Leguizamón: êl se firmaba Leguiçamo.

3 Bautista Antonelli. Diego Angulo Iñiguez. Madrid, 1942. 
levantados por el célebre ingeniero de Felipe II. Uno (Torres Lanzas 35) que representa la isla de Ulúa con el reparo que podría hacérsele; otro (Torres Lanzas 37) describe simplemente el fuerte y el reparo; en seguida tenemos (Torres Lanzas 36) la perspectiva del reparo del fuerte y de la población que existió en Ulúa. Pueden verse las naos amarradas a gruesas argollas empotradas en el muro. Es curioso notar que esas argollas aparecen todavia en las vistas del siglo $\mathrm{xIX}$ de la vieja fortaleza. Finalmente tenemos (Torres Lanzas 41) la planta de San Juan de Ulúa con su fortificación y el reparo de las naos. Como supone perfectamente el señor Angulo, algo debe haberse hecho de los proyectos de Antonelli, ya que, fundamentalmente, el plano de la fortaleza definitiva coincide con estos proyectos, a pesar de las críticas que les hizo el capitán Ochoa de Leguízamo y que constan en dos planos, uno fechado en Buitrón el 7 de enero de 1590 (Torres Lanzas 40) y otro que el mismo autor (Torres Lanzas 42) supone data le 1591, pues carece de fecha, en que las críticas de Leguizamo suben de punto contra el proyecto de Antonelli.

El plano más antiguo que corresponde a la ciudad de la Nueva Vera. cruz parece fechado en 1608 . Pero no es sino una repetición de los dos planos de Antonelli : uno que reproduce la costa desde el río de Medellín hasta el de la Antigua a cuyas márgenes aparece la vieja Veracruz. Frente a Ulúa, con el nombre de Buitrón, se ve otra ciudad. (Figs. 2 y 3 )

Uno de los planos más bellos de la ciudad de Veracruz es el que mandó reproducir en Florencia don Francisco del Paso y Troncoso. No es propiamente un plano, sino una vista panorámica que muestra la ciudad recién fundada, en bellos colores. La representación cromolitográfica es tan perfecta que tenemos idea que fué sacada del original; no está fechada ni firmada, pero la leyenda que ostenta está escrita por la misma mano que firmó un plano semejante del puerto de Acapulco, el cual sí está firmado por Adrián Boot, ingeniero y cosmógrafo flamenco que estuvo en México a principios del siglo xvrr y estudió especialmente las obras del desagūe. El señor Troncoso ha hecho un estudio detenido de este plano reduciéndolo a la verdadera planta y adaptándolo a las calles actuales de Veracruz. Supone que data de 1615 y titula su trabajo "La Ciudad de Tablas" porque, efectivamente, la mayor parte de las construcciones aparecen de madera, pintadas de amarillo para diferenciarlas de la parte de mampostería qute es roja. Aunque la ciudad es provisional, sus dimensiones son casi las de la actual Veracruz, lo cual indica la importancia que desde entonces tenía ésta. Aparece un pequeño muelle y varias iglesias, si bien parecen cons- 
truidas de prestado. La interpretación del señor Troncoso es exacta, naturalmente en cuanto a la identificación de los edificios, pero la disposición de las calles no es acertada, pues algunas aparecen de una anchura desmesurada, cosa que, bien sabido es, no existió nunca en las poblaciones coloniales. $\mathbf{Y}$ asi la reproducción que hace el docto historiógrafo, presenta un aspecto mucho menos tubanístico que el propio original en perspectiva. De desearse sería la reimpresión del trabajo del sefior Troncoso. (Fig. 4)

En el siglo xvi aparecen muchos planos de nuestra ciudad, to cual es natural si se piensa que todos los arquitectos e ingenieros militares tenían que trabajar en Ulúa del que dependia directamente la ciudad.

Un plano del siglo xvir, al que tampoco puede fijarse fecha exacta es el que aparece en la Relación de Juan de Avila, del saqueo de Veracruz en 1683. * No hay indicación de dónde puede proceder este plano y sólo se sospecha que existió en el Archivo General de la Nación.

De 1663 data el plano de Veracruz hecho por su gobernador don Fernando de Solís y Mendoza con motivo de las fortificaciones que levantó al tener noticia de que la ciudad de Campeche había sido ocupada por el enemigo (Torres Lanzas 58).

En el mismo año de 1663, el ingeniero de su Majestad don Marcos Lucio propone la fortificación de la ciudad y traza su planta ('Torres Lanzas 59).

El mismo Marcos Lucio presenta el año de 1670 un plano del castillo de Ulúa, relativo a diversas obras que habia que hacer y que se habian hecho en conformidad con una visita del Virrey Marqués de Mancera (Torres Lanzas 63).

La idea de fortificar la población debe haber surgido desde bien temprano; pero la primera noticia que tenemos de ella aparece en un plano que data de 1683 y cuyo título reza: "Planta real para circunvalar la ciudad de la Nueva Veracruz hecha por el ingeniero don Francisco Pozuelo y Espinosa el 13 de agosto de 1683." El mismo ingeniero presenta el 20 del mismo mes un plano de la misma ciudad según reconocimiento que ha hecho personalmente. Sin embargo, no fué sino un siglo después cuando se levantó la muralla de Veracruz; en enero de 1741 formó el proyecto el ingeniero don Félix Prósperi, de quien hablaremos después, según el plano que vió el historiador del puerto, Lerdo. ${ }^{\circ}$ Un ingeniero militar famoso, Jaime

4 Reproducido en Alcancía, México, 1937.

5 Apuntes históricos de la Heroica Ciudad de Veracruz. Por Miguel M. Lendo de Tejada. Tomo I. Mérico, 1850. Pág- 299. 
Frank que trabajó en la Nueva España en la primera mitad del siglo xvir, nos dejó una planta de la ciudad de Veracruz y del castillo de Ulúa (Torres Lanzas 85). Es indudable que después de estos intentos se lleva a cabo la fortificación de la plaza, rodeándola de una muralla como la tenía Campeche y otras poblaciones virreinales. Sin embargo, la fortificación de plazas amuralladas no tuvo en Nueva España la misma acogida que en la metrópoli. Las grandes ciudades no fueron nunca amuralladas, quizá porque no se presentó la necesidad de ello o porque no fué posible, como en la capital del virreinato, en que el subsuelo pantanoso impedia levantar murallas y con otra circunstancia: que los indios agrupaban sus casas alrededor de la población española, construída en un principio por la traza y que ésta se iba ensanchando continuamente a expensas de aquéllos por lo que no era posible definir en un solo momento qué parte era la población española y cuál correspondía a la indígena. Por eso son interesantes esos planos de Veracruz en que aparece la ciudad rodeada de murallas que no fueron, por otra parte, de verdadera fortificación como las españolas de Avila o de Lugo, sino un simple paredón, como dice don Francisco del Paso y Troncoso, con baluartes en los ángulos más peligrosos y puertas fortificadas. Aún asi y todo, es interesante la vista de Veracruz rodeada de sus muros. Durante el siglo xvirr los planos de Veracruz se multiplican considerablemente. No sólo en España y América se dibujan, sino en la misma Francia comienzan a aparecer asi, del año de 1720, tenemos un "Plan de la Vera Cruz avec les isles de St. Jean de Luz situés aux Indes occidentales d'Espagne", que más tarde lo encontramos reproducido en un curioso libro que narra las piraterias de los filibusteros publicado en Francia en 1775. Quizá sea el mismo que un catálogo francés asigna al año de 1780 . (Fig. 5.) Este mismo plano se halla copiado torpemente en un libro de historia de América que no he logrado identificar. (Fig. 6.) El interés de los franceses por tener planos de Veracruz se explica por el deseo de facilitar a sus corsarios el ataque a dicha ciudad; así el año de 1762 aparece el "Plan de la rade et ville de la Vera Cruz.--Par le Sr. Bellin, Paris". Una versión, acaso italiana, de este plano la tenemos en el año de 1770 pues el titulo es exactamente igual traducido a dicho lenguaje. Cinco años más tarde aparece un plano inglés o norteamericano, ya que tanto franceses como ingleses se interesaban por el principal puerto de la Nueva España. Los franceses siguen trabajando intensamente en eso y asi tenemos en 1798 el plano arreglado y dibujado por G. de Bois St. Lys, que el catálogo describe como magnífico, a colores y de una bella ejecución. Pero naturalmente interesaba más a los franceses aprovecharse de los planos levantados por los ingenie- 
ros españoles, como lo demuestra el hecho de que en 1802 se reproduce, por el Depósito General de la Marina, el plano levantado por don Bernardo de Horta, del cual hay una edición en 1807 y más tarde, en 1820 aparece otro plano francés del puerto de la Vera Cruz.

Los planos españoles o coloniales del siglo xvrir son de suma importancia, pues nos dan a conocer los trabajos de todo aquel grupo de ingenieros militares que florecieron en esa centuria, entre los cuales hay que mencionar a don Jerónimo de Pineda, 1734; a los ingenieros Navarrete y Cortés, 1735; a don Féliz Prósperi, 1733 a 1738. Prósperi fué de los más notables ingenieros militares y publicó un curiosísimo libro sobre fortíficaciones llamado La Gran Defensa. El fué quien hizo las murallas de Veracruz, como hemos dicho. En 1739 aparece don N. Lontes. En 1751 levanta el plano de Veracruz el capitán de fragata don Francisco de Villa Franca y diez años más tarde existe un levantamiento igual de Gutierre de Hevía. Un poco más adelante aparecen dos importantes ingenieros que trabajan juntos: don Carlos Luján y don Agustín López de la Cámara Alta; por la misma época, en 1759, don Lorenzo de Solís levantó planos de la ciudad y del castillo. Agustín López de la Cámara Alta independientemente de sus trabajos personales colabora con varios ingenieros: don Francisco Crespo Ortiz y don Pedro Ponce; este último presenta también un plano de Veracruz trazado por él mismo. En 1765-66 aparece don Manuel de Santisteban; a fines del siglo don Bernardo de Horta figura levantando un plano de Veracruz y el puerto, que después ha de ser copiado por los franceses.

Un plano de Veracruz de los más bellos que existen ${ }^{6}$ data sin duda de fines del siglo xvirt o principios del siguiente. Es manuscrito, bellamente ejecutado a la acuarela, $y$ en la parte inferior aparecen los edificios de la ciudad casi en perspectiva, correspondiendo al plano. En la misma hoja y del mismo autor está el plano del castillo de San Juan de Ulúa como quedó en definitiva, con su corte transversal. Desgraciadamente no se sabe quién ha sido el autor de estos bellisimos planos.

En 1800 cambia la tendencia de los planos de Veracruz. La ciudad había crecido tanto que se pensó en ampliarla. El autor del proyecto fué don Manuel Agustín Mascaró y el plano recibió la aprobación del ingeniero Costansó que parece haber sido el supervisor general de las obras de arquitectura, en la Nueva España, en todo ese tiempo.

6 Debo su conocimiento a mi estimado amigo don José Antonio Pérez Porrúa. 
El plano, si es el que me figuro, prolonga las calles de la ciudad hacia la parte opuesta a la costa, de manera que las murallas vienen a formar un recinto rectangular. La parte nueva no es muy extensa, pues comprende sólo una mitad de lo que ya estaba construido. Alrededor de la muralla se pensó plantar una calzada de árboles que protegiera a la ciudad de las invasiones de arena y que fijara un poco los médanos. Si debemos lamentar que esta ampliación no haya sido llevada a cabo, no podemos menos de pensar en el grave error que se cometió cuando la ciudad fué ensanchada al no conservar sus murallas, rodearlas por el exterior con una calzada de árboles que formase un paseo y construir fuera de ella la parte nueva. El sistema empleado fué el peor posible: se derribaron las murallas, se prolongaron las manzanas en dirección opuesta a la costa y se dejó la ciudad libre a todos los vientos que pudieran azotarla. (Fig. 7.)

Después de la Independencia buen número de planos de Veracruz siguen levantándose. Hay que mencionar desde luego el hermosísimo plano grabado en Londres en que aparece Veracruz como puerto del Golfo en el Portulono que se levantó desde 1807 y fué publicado por orden del Presidente don Guadalupe Victoria en 1825. Aunque la ciudad octupa un espacio pequeño, puede verse perfectamente el trazado de sus calles y el contorno de sus murallas. (Fig. 8.)

Un plano cuyo origen no he identificado, sino hipotéticamente, y que forma parte de mi colección, es el que a continuación estudio: Se trata de un grabado en cobre, impreso en tinta sepia, que reproduce la costa desde la punta de Mocambo hasta la punta Gorda. La ciudad de Veracruz se encuentra casi al centro y está delineada la muralla, pero las calles no aparecen detalladas. El castillo de Ulúa figura también en el plano, lo mismo el grupo de islas y arrecifes que se encuentran a la entrada del puerto. Habiendo adquirido el grabado suelto, me parecia imposible determinar de qué libro provenia, pero revisando la Bäbliografía de Veracrug encontré una "Estadística del Estado Libre y Soberano de Veracruz", publicada en 1831, y parece casi seguro que este grabado pertenece a ese libro y es por lo siguiente: el tipo de letra corresponde a la época; por ese tiempo se usaba mucho de los grabados impresos en este color sepia. Hay, por ejemplo, edición de las Fábulas del Pensador Mexicano con ilustraciones en este tono sepia o naranja. Otro dato que viene a confirmar la suposición es la medida del libro que es de $200 \mathrm{~mm}$. de altura. La 1ámina de cobre del plano mide 180 , de modo que corresponde perfectamente en el tamaño. (Fig. 9.) 
A mediados del siglo XIX se publicó un grupo de planos en litografía que quizá constituye una de las obras más bellas e interesantes de nuestro estudio. No es posible fijar la fecha exacta de todos estos planos porque no consta en ellos. Algunos eran regalos a los suscriptores de periódicos, por ejemplo, los del periódico Ilamado "La Sociedad". (Figs. 10 y 11.) Los más importantes son tres: plano de Veracruz y sus inmediaciones, impreso en la litografía de Decaen; "Veracruz tomado en globo", dibujado por Francisco García y litografiado por Casimiro Castro en la casa de Decaen, $y$ otro plano en que aparece la ciudad con sus alrededores. E1 plano topográfico de Veracruz y la vista tomada en globo fueron reproducidos, aunque imperfectamente, en un folleto acerca del puerto del que fué autor don Ildefonso Estrada y Zenea y después copiados en varias publicaciones como en la Historia de Jalapa de Rivera Cambas.

$Y$ después de esta época que puede llamarse de los planos antiguos de Veracruz, comienza la era moderna. Aparece ya la ciudad sin murallas y los planos presentan técnica científica. El primer plano científico de Veracruz en este tiempo parece ser levantado por el ingeniero I. P. Guźmán el año de 1878 que después sirve de base a muchos planos posteriores. En 1907 la Comisión Geográfica Exploradora levanta su plano fundado en el de Guzmán y en los datos de las obras del puerto. En 1914, finalmente, tenemos el plano del ingeniero T. de P. Guzmán, descendiente del anterior, a gran tamaño $y$ hecho con todo cuidado.

Es indudable que los ingenieros de las obras del puerto levantaron un plano que supongo es el que figura en este catálogo.

Para concluir esta fatigosa reseña hay que mencionar los planos levantados por la Comisión Planificadora del puerto en que intervino de modo primordial el arquitecto Carlos Contreras. Según entiendo la Junta Forestal hizo igtalmente un levantamiento para las obras de reforestación de la ciudad, llevado a cabo por el benemérito ingeniero Miguel Angel Quevedo.

Finalmente, para completar este estudio se formula a continuación el catálogo de todos los planos que he visto o de que he tenido noticia. Las papeletas consignan los datos que han llegado a mi alcance. Seguramente, y en un plazo no muy lejano, estas papeletas se verán aumentadas por nuevos hallazgos de planos de Veracruz, que nos permitirán poseer la cartografía completa del puerto. Por hoy nos contentamos con poner la primera piedra de este abigarrado pero interesante edificio. 


\section{Catalógo de los planos de veracruz y CASTILlo DE SAN JUAN DE ULUA}

\section{Siglo XVI.}

Veracruz, M. S.-'Es copia, mbs que de un plano de una vista de Veracruz, antes que el puerto que existía en la Antigua se pasara al lugar actual. El original corresponde. pues, al siglo XVI, pertenece al S. D. José Fernando Ramíxez, y forma parte de un portulano mannectito, con notas acerca de los derroteros y de las navegaciones, obra de alguno de los pilotos de entonces. El cuaderno original es en demasia curioso e importante pare la historia de la navegación, no sólo en Amética, sino también en Europa". Cartografía, pp. 208-209. núm. 1362.

\section{1590.}

"Prespetiva de rreparo y fuerte y población de San Juan de Vlúa". 27 enero 1590. Bautista Antonelli.

A colores. $0.55 \times 0.41$.

Toeres Lanzas Num. 36. Lo reprodujo Troncoso en fototipía en negro a tamaño menor y lo publica Angulo en su folleto Bautista Antonelti.

\section{1590 (?)}

"Plante de San Jhoan de Ulua assi de la fortificación que tiene como del reparo de las naos; las líneas coloradas es lo viejo y las verdes es vn reparo que se ha de hacer hasta que su M.d mande q. se fortifique este puerto de propósito. Batista Antonelli."

A colores. $0.42 \times 0.28$.

Torres Lanzas. Núm. 41. Como carece de fecha le supone con justicia la de 1590.-Reprodujo este plano don Francisco del Paso y Troncoso, en fototipia negra y a menor tamaño. 
4. 1590 .

"Plano de la ciudad proyectada en Buitrón". Por Pedro Ochoa Leguisamo.

A colores. $0.43 \times 0.87$

Torres Lanzas Núm. 38.

5. 1590 .

'Planta del fuerte y reparo adonde se recogen las flotas que van a San Juan de Ulúa. Provincia de la Nueva España..." S. Jaan de Ulúa 27 enero 1590. Bantista Antonelli.

A colores. $1.12 \times 0.40$.

Torres Lanzas. 37.

6. 1590 .

"Planta y Discripción de la Isla de San Jhoan de Ulúa y de la manera que se podria fortificar con el reparo que tengo tratado en la otra planta..." S. Juan de Ulúa 27 de enero de 1590 . Bautista Antonelli.

A color, $0.55 \times 0.82$.

Torres Lanzas, Núm. 35. Lo reprodujo don Francisco del Paso

y Troncoso en fototipía en negro a menor tamaño.

7. 1590 .

"Plano de la fortaleza de San Juan de Ulúa, con informes sobre sus obras por el Capitán Pedro Ochoa de Leguísamo fechado en Buytron 7 de enero $1590^{\prime \prime}$.

Torres Lanzas, núm. 40.

8. 1591. (?)

"Diseño o traza del baluarte que se hace de prestado en el puerto de San Juan de Ulua, trazado por Antonelli con informe al pie, đel Capitán Pedro Ochoa de Leguizamo haciendo ver los inconvenientes de su construccion".

$0.35 \times 0.21$.

Torres Lanzas, núm. 42. Supone que es de 1591 pues las indicaciones de Antonelli datan del año anterior.

9. 1608 .

"Perspective of San Juan de Ulúa, after Bantista Antonelli, 1608 ". Se encuentra en las Cartas, Instrucciones y Cédulas a Antonelli (V. Bibliografía).

Aparece la fortificación como en el plano Núm. 36 de Torres Lanzas, con nn nuevo lienzo de fortificación rematado en una torre.

10. 1608 . $1608 "$.

"Map of the coast of Merico near San Juan de Ulúa, after Bautistz Antonelli. 
Aparece en el mismo trabajo que el plano anterior. Abarca desde el río de Medellin hasta el de la Antigua a cuya margen se ve la "Bera Cruz". En frente de Ultia en la costa otra ciudad con el nombre de "Buitrón".

Dibujo en extremo convencional.

11. 1615.

"Puerto de la Vera Cruz nueva con la Fuerza de S. Juan de Ulía en el Reino de la Nueva España en el Mar del Norte. Tiene la ciudad de longitud 1200 varas. La Fuerza tiene de Longitud 195 varas. Tiene la canal deade tierra ata la Fuerza 200 vatas". "Firenze Lit. A. Raffoni Piazza S. Croce 20".

Reproducido a colores por orden de D. Fco. del Paso y Troncoso. -El original pertenece a Fro. Orozco Muñoz.

12. 1615 .

"Curso del Tenoya por la ciudad de tablas".

Arreglo del plano anterior hecho al parecer por don Franciaco del Paso y Troncoso para ilustrar la carta que eacribió al Gobernador de Veracruz, don Teodoro Debesa. Como puede apreciarse la reproducción es muy imperfecta: las calles presentan a veces una anchara no usada en la epoca colonial, lo que le da escaso aspecto urbanfstico, contrariamente al original.

13. Siglo Xvil.

"La ciudad y castillo de 12 Veracruz".

Reproducción en fotograbado de línea de una revista existente en en Archivo Gral. de la Nación, del siglo Xvill ég. F. Gómez de Orozeo. Colorido a mano.

Relación de Juan de Avila del saqueo de Veracruz en 1683.Ediciones Alcancía. Mér. 1937.

14. 1663.

"Planta de la Nueva Ciudad de La Veracruz en la forma que por la acelerada nneva de baber ocupado el enemigo el Puerto de San Francisco de Campeche, la puso su gobernador Don Francisco Solín y Mendoza, etc."

A colores. Arch. Ind. $0.58 \times 0.43$.

Torres Lanzas, núm. 58.

15. 1663.

"Planta de la ciudad de la Nueva Veracruz que propone para mayor aguridad de ella, etc." Por el Ing. de S. M. D. Marcos Lacio.

A colores. Arch. Indias. $0.58 \times 0.43$.

Torres Lanzes, ntim. 59. 
16. 1670 .

"Planta y demontración del castillo e isia de San Juan de Ulúa y el plazel como hoy está con los padrastos del almagazén, ramales $Y$ unas paredes de la yglesia por acabar $y$ la media luna por cerrar en ángulo agudo, que por vista de ojos del virrey Marqués de Manzera ae mandó demolet por sez padrasto para el mayor seguro del castillo de San Jaan de Utúa, del año 1670'. Por Marcos Lucio, ingenieto militar de S. M.

A colores. $0.29 \times 0.24$.

Totres Lanzas, núm. 63 .

17. 1683 .

"Planta Real para circumbalar la ciudad de la nueva Veracruz, hecha por el Ingeniero Don Francisco Posuelo y Espinosa en 13 de agosto de $1683^{\prime \prime}$.

A colores. Arcb. Ind.

Torres Lanzas. núm. 74.

18. 1683.

"Planta de la Nueva Veracruz según resulta del reconocimiento hecho por el Ingeniero Don Francice Posuelo y Espinow en 20 de agosto de 1683".

A colores. Arch. Ind.

Tórres Lenzas, núm. 75.

19. 1689 .

"Planta de la cindad de la Nueva Veracraz y ou castillo de San Juan de Utia con el disinio de una cindadela sobre un arrecife enfrente del baluarte de Caleta, por el Capitín Don Jayme Franck. Ingeniero mititar por $\mathbf{S}$. M'".

A colores. Arch. Ind.

Torres Lanzas, núm. 85.

20. 1720.

"Plan de la Vera Croz avec les isles de St. Jean de Luz situées aux Indes Oc. cidentales d' Espagne"r.

Americana, pág. 139, núm. 32776.

21. 1733 .

"Plan de la Vera-Cruz. Port du Mexique".

Grabado en cobre. La ciudad rodeada de murallas. En la playa de

la Caleta: Fort projeté. El castillo de Ulta como terminado.

Histoire de L'iste Espagnole au de $S$. Domingne. Por le $P$.

Pierre-François Xavier de Charlevoix. Tomo iIs. Amsterdan,

1733. El plano se encuentra entre las páginas 176 y 177. 
22. 1734.

"Plano de una parte de Veracruz, puerto y Castillo de San Juan de Ulúa con los proyectos para la fortificación, delineado por don Jerónimo Pineda. Año de 1734".

\section{Mapas de Ultramar}

23. 1735.

"Plano que demuestra el fuerte de Veracrua y Castillo de San Jpan de Ulúa con los proyectos para la seguridad del Puerto, prolongación y ensanche de las Marallas y Muelle, Quarteles para los Dragones, etc., remitido en el año de 1735 por los Ingenieros Navarro y Cortés".

\section{Mapas de Ultramar}

24. 7736 .

"Plano de la ciudad de Veracruz y Castillo de San Juan de Ulúa, con los proyectos para sa defensa, delineado por el Ingeniero Prosperi". Año de 1736.

\section{Mapar de Ultramar}

\section{1736 .}

"Plano de la ciudad de Veracraz y Castillo de San Juan de Ulúa con loe proyectos de fortificaciones, por el Ing. Félix Prosperi". M. S.

Soc. Geog. y Estd. 2\% Mesa cajón 12.

Mirabal, pisg. 180.

Duplicado, acaso, del anterior.

26. 1738 .

"Proyectos concernientes al Puerto y Plaze de Veracraz y Castillo de San Juan de Ulúa por don Félix Prosperi, quien los remitió el año de 1738".

\section{Mapas de Ultramar}

27. 1738 .

"Elevación del proyecto de la obra que cubre el Puerto de Veracruz por don Fellix Prosperi". Afio de 1738.

\section{Mapas de Ultramar}

\section{1739.}

"Plano del Cautillo de San Juan de Ultáa situado en la Isia de Gallega y proyecto de una cindad que se podia construir en dicha Isla, delineado por don N. Lontes en 1739."

\section{Mapas de Ultromar}

29. 1741 .

"Plano y explicación de Boterios proyectados en la Isleta y frente del Castillo de 
San Juan de Ulúa que mira a la Canal (sic) Nueva, remitido por el Gobernador de Vexacruz en 1741."

$$
\text { Mapas de Uitramar }
$$

30.

Otro Plano continuación del anterior.

$$
\text { Mapas de Ultramat }
$$

31.

Otro relativo a los dos anteriores, remitidos todos tres por don Félix Prosperi.

$$
\text { Mapas de UItramar }
$$

32. 1742 .

"Plano del Castillo de San Juan de Ultá remitido por el oydor Villavicencio en 12 de mayo de $1742 . "$

$$
\text { Mapas de Ultramar }
$$

33. 1742.

"Plano de la contraguatdia becba en el Castillo de San Jna de Ulúa, remitido por el Oydor de México Villavicencio en 1742."

\section{Mapas de UItramar}

34. 1746.

"Plano del castillo de San Juan de Ulta en que se manifiestan las obras executadas por don Agustín de la Cámara Alta con las contraguardís provectadas por el mismo y las correcciones que tubo por conveniente el Ingeniero Director don Manuel Santistevan en el año de 1746."

\section{Planos de Ultramar}

35. 1749.

"Plano y perfil del Muelle de Veracruz, por don Félix Prosperi en 1749."

$$
\text { Planos de Utramat }
$$

36. 1751 .

"Plano del puerto de Bera Cruz". Presentado por el capitán de Fragata D. Francisco de Villafranca con una representación baciendo ver los inconvenientes de sacar piedra del bajo de la Gallega como se hace en la actualidad.-.-5 de mayo de 1751.

A colores. Arch. Ind.

Torres Lanzas, nóm. 181. 
37. 1751 .

"Planos sobre los cuales se fabrican los Quarteles de Dragones de Veractuz por el citado Prosperi en 1751."

$$
\text { Mapas de Ultramar }
$$

38.1752 .

'Plano del Puerto de Nueva Veracruz nuevamente levantado por el capitán de Navio don Gutierre de Hevia. Año de 1752."

\section{Mapas de Uliramar}

\section{1757.}

"Proyecto del Muelle de Veracruz, proyectado y aprobado por el Rey. que se ha de construir en el Puerto, por don Carlos Luxan año de 1757."

\section{Mapas de Ultramar}

40. 1759.

"Plano del Puerto porción, de la Plaza y Castillo y surgidero de Veracruz la Nueva, con sondeos, deacripción dél, sus Laxas viriles y Bajos que se comprenden en él, por don Lorenzo Solis en 1758."

\section{Mapas de Vitramar}

41. 1759.

"Plano de unz porción del Castillo de San Juan de Ulúa, con el proyecto de la reedificación del Muelle, por don Lorenzo Solís en 1759."

\section{Mapas de Ultramar}

42. 1760 .

"Plano del perfil del edificio que arriba se cita (Cuartel de Infanteria) construidoe por el mismo Solis en 1760."

\section{Mapas de Utramar}

43. 1762 .

"Plan de la tade et ville de la Vera-Cruz."--Par le Sr. Bellin. Paris, 1762.

$0.21 \times 0.17$.

Americana, pág. 140, núm. 32783 .

44. 1762 .

"La Vera Crux, ville du Mexique." Par le Sr. Bellin.-París, 1762. 0.21 x 0.17. Americana, pág. 140, núm. 32784.

Aparecen como diversos en el mismo catálogo de este plano y el anterior. 
45. 1763.

"Plano de la Ciudad de la Nueva Veracruz, Castillo de San Juan de Ulúa, diseños de los navios que habia en la canal que media entre ambos lugares, etc., etc."

Sacado de su original por orden del Exmo. Sr. Marqués de Cruillas. Virrey de esta Nueva España. Mex. y mar. 1763, Br. Fco. de $A$ colones.

Zúñiga y Ontiveros.

Torres Lanzas, núm. 218.

46. 1763 .

"Plano parcial del Castillo de San Juan de Ulúa al frente de la ciudad de Veracruz que manifiesta el estado en que se ballaba antes de la guerra y el modo que queda con las nuevas obras hechas para su defenza $y$ como deben quedar acabados los proyectos, por don Pedro Ponce en 1763."*

\section{Mapas de Uliramar}

47. 1763.

"Plano parcial del puerto de Veracruz y sus contornos, manifestíndose las situaciones de las dos bocas de ríos el príncipal de Medellín y el de Vergara, por don Agustín López de la Cámara AIta, don Francialco Crespo Ortiz y don Pedro Ponce. en el año de 1763."

Epist. N. F. T. XV p. 23.

48. 1763.

"Plano de la Plaza de Veracruz, an Castillo de San Juan de Uláa con la descripción del canal, viriles, situación", etc., ete. Vecacraz, 20 abril 1763. Por don Agustin Lópex de la Cámara Alta.

A colore.

Ignoro si este plano es el anteriot.

Torres Lanzas, núm. 220.

49. 1763.

"Plano de la ciadad de Veracruz en que se espresan las obras y reparos que se han executado hasta marzo de 1763 . por don Ricardo Ayaier."

\section{Planos de Ultramar}

50. 1764 .

"Plano del Castillo de San Juan de Ulúa en que se manificstan las obras executadas por el Ingeniero don Agartín de la Cámara." Remitido en 1764.

\section{Mapas de Ultramar}

51. 1764 .

"Plano de la ciudad de Veracruz, su Castillo de San Inan de Ulúa, el surgidero o amarradero de los navios del Rey y del Comercio Español con el proyecto de for- 
tificar esta ciudad para dejarla en una Moral defensa..." Veraeruz, 10 sep. 1764. Por D. Pedro Ponze, ingeniero.

A colores.

Torres Lanzas, núm. 224 .

52. 1765 .

"Plano de la plaza de Veracruz, su puerto y castillo de San Jaan de Uíá con el proyecto general de sus fortificaciones. Modo $1{ }^{\prime \prime}$ Por D. Manuel Santistevan. Veracruz, 25 de agosto de 1765 .

Otro igual. Modo 39 de la misma fecha y por el mismo.

Torres Lanzas, núm. 228 y 229.

53. 1766 .

"Cuatro planos que demuestran la cindad de Veracruz, sus contomos e inmediaciones con el proyecto de la ciudadela, por don Manuel de Santiestaban, en 1766."

Epist. N. E. T. XV. p, 25. Pareze que se refiere a los anteriores con dos más que no cita Torres Lanzas.

54. $176 \ldots$ ?

"Plano de la ciudad de Vetacraz en que se manifiestan las obras y repatos hechos hasta marzo de $176 \ldots$ ?t

\section{Mapas de Ultramar}

55. 1770.

"Piano della rada e della cittá della Veracruz." $0.23 \times 0.27$.

Americana, pág. 140, núm. 32786.

56. 1773.

"Plano de la Nueva Veracruz por el bachiller don Francisco de Zániga y Ontiveros de orden del virrey Cruillas, en 1773."

Epist. N. E. T. XV, p. 23.

57. 1774 .

"Quatro Planos del estado en que se ba de poner el Castillo de San Juan de Uláa y las obras que se deben executar para eate fin, determinado en la Junta mandada formar por su Magestad en dicha Plaza de Veracruz. Delineados por don Manuel Santisteran en 1774."

\section{Mapas de Uttramar}

58. 1775 .

"Plano de la plaza de Veracruz, su castillo de San Juan de Ulúa y puexto, donde se manifiesta el proyecto para la seguridad de los navios del Rey y del comercio, sacado de los ramales de N. O. y E. E., para que anden sin peligro en que están, logrando la ventaxa de entrar con el $N$. $y$ doblado la punta del Est. dado puedan agegurarse: 
estando adactado (sic) a las moiores ventaxas, y menos gastos. Veracraz ... de noviembre de 1775. (Fimado). D. Carlos Luxan. Agustín López de la Cámarz Alta." M. S. Original.

Cartografia, p. 206. núm. 1338.

59. 1775.

"Plan of la Vera Cruz from Spainsh draughts". $0.20 \times 0.31$.

Americana, pág. 140. núm. 32793.

60. 1775.

"Plan de la Vera Cruz apec les Isles de St. Jean du Luz Situées aux Indes Occidentales d' Espagne."

Aparece en el curioso libro "Histoire des Aventuriers Filibustiers par Alexandre Olivier Oexmelin. A. Trevoux, 1775."

Acaso es el mismo que en Americona, núm. 32782 se supone es de "vers 1780 ".

$61 . \ldots ?$

"Plano de Veraciraz con la Isla de Sn. Juan de Ulúa aituadas en las Indias Occidentales Españolas."

Es un dibujo burdo copiado del plano anterior.

62. 1780 .

"Le plan de la Vera Cruz avec les islas de St. Jean de Luz situées aux Indes Occidentalea d' Espagne."

Dreśz et gravé par Liebanx. Vers. 1780.

$0.16 \times 0.21$.

Americana, pág. 140, nóm. 32782.

63. 1780 .

"Vera Cruz dans le golfe du Mexique."

$0.18 \times 0.12$.

Americana, pág. 140, núm. 32788.

64. 1781 .

"Plano de parte del recinto de Veracruz."

Torres Lanzas, núm. 364.

65. 1795.

"Plano del puerto de Veracruz." ¿Por don Bernardo de Orta?

Torres Lanzes, núm. 458.

66. 1798.

"Plan de la villa de la Vera Cruz.-Plan du port de la Vera Craz réduit et desiné por G. de Bois St. Lys. 1798. Magnifíque plan manuseric colorie, d une fort belle execution."

$0.40 \times 0.60$.

Americana, pdg. 140, nứm. 32796. 


\section{1860 .}

"Plano de ha Cindad de la Nueva Ven Cruz, con el proyecto de sa ampliación." Por don Manuel Agrotín Macaró con aprobación de Costanzó. 3 de mayo de 1800 .

Torres Lanzas, ntim. 479.

68. 1802.

"Port de la Vera Cruz a la cote occidentale del golfe du Mexique d'aprés le plan levé par Dn. Bernardo de Orta. Publié au dépot général de la marine en 1802."

$$
0.41 \times 0.51 \text {. }
$$

Americona, pág. 140, núm. 32797.

69. 1807.

"Plan du port de Vera Cruz dresće par Don Bernardo de Ota. 1807."

$0.22 \times 0.29$.

Ameticana, pág. 140. núm. 32800.

70. 1820 .

"Port de la Vera Cruz (1820)."

$0.18 \times 0.26$.

Americana, pàg. 140, núm. 32803.

71. 1825 .

"Plano del puerto de Vera Cruz.-Levantado en 1807, publicado por orden del Exmo. Señor Dn. Gazdalupe Victoria primer Presidente de la República."-México. Año 1825 .

Grabado en cobre, bagnifico. Forma parte del Portulano becho por orden del mismo gobernante. obrz de primer orden no igualada hasta abora.

\section{1841 .}

"Introducción del agus del Janapa en Veracruz." 1841. M. S. Cartografia, p. 226. ntm. 1726.

73. 1843. a 1844.

"Veracruz." - Grabado en madera, en el calendario de Cumplido correspondiente

De los curiosos con el proyecto de una ampliación y con el detalie de todos sus baluartes. calles y edificios.

Cartografia, p. 267, ntam. 2274, sin dar fecha.

74. 1847 .

"Mrpa de la ciudad y puerto de Vera-Croz y castillo de San Juan de Ulúa en el bombardeo por el ejército mericano."

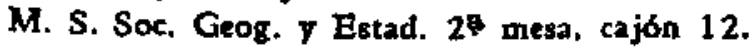

Mirabal. pág. 180. 
75. 1847 .

"Mapa de la cindad y Puerto de Veracruz $Y$ castillo de Sn. Juan de Ulía en a bomberdeo por $A$ ejército de los Estado Unidio en d atio de $1847^{\prime \prime}$.-Publìcado por el profesor de Ceografía del Colegio Mititar, y delineación de otros colegios $F$. Soto, quien lo dedica al E. S. Director Gral. de Ingenieros Da. Ignacio Nava Y Vi. Ilamil.

En litografia. Lit. Rocha. Calle de Tacuba N. 14.

76. 1849.

"Plano de la plaza de Veracraz." M. Robles.

Soc. Geog. Y Estad. 24 mesa, cajon 12.

Mirabal, pág. 183.

$77,1854$.

"Plano de la plaza de Veracruz y sus alrededores." Teniente Corouel M. Robles. Soc. Geog. Y Eatad. 2 meza, cajón 12.

Mirabal, pág. 184.

78. 1854.

"Plano topográfico de la Heroica ciudad de Veracruz.-Año de 1854."--"Ptopiedad de Dn. Domingo Bucean." Juan de Dios Sánchez lo litografio. Lit. de Sánchez y Hermano. $2^{4}$ ce de la Merced. 172. Veracruz.

Aparece una copia reducida del miamo en la "Hirtoria de Jalapa $y$ revolnciones del Eatado de Veracruz". de M. Rivera Cambal. Tiene las firmas: "V. de Mntguia e Hijos". L. Garces dibo

Cattografla, p. 267, ntim. 2275.

79. 1857 .

"Plano de la plaza de Vecacruz $\mathbf{y}$ sus alrededores con las obras de fortificación que se proyectan para ponerla en estado de defents." Affo de 1857.

M. S. original en la sección de Cartografia del Instituto Ran-

americano de Geografia e Historia. Ním. 1355 du Catsloro.

80.

"Vista del castillo de Sn. Juan de Ulta. de la cindad de Veracraz y de ans al-

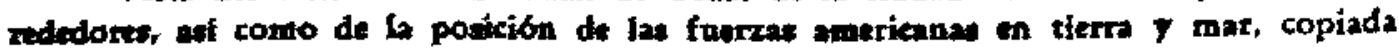
del modelo en relieve becho por Mr. Clairac, ingeniero militar de fortificación."

En la "Historia de Jalapa y revoluciones del estado de Veracrus"

por M. Rivera Cambas. Tamailo pequeto. Pirmado: "V. de Mar-

guía e hijos. L. Gerck. dibor.

81.

"Ptano de Vermeraz y sas inmediaciones": Lit. de Decten.

Obsequio a los Sres. Suscritores de "Le Sociedad".

Cartografia, p. 267. ntm. 2277.

Mirabal, pág. 155. 
82.

"Veracruz tomada en globo." Dib. Fco. Garcia. Lit. C. Craro. Mexico. Imp. Litog. de Decaen.

Obsequio a los Sres. Suscritores de "La Saciedad".

Cartograffat, p. 267, ntimi. 2276.

83. 1864.

"Veracraz." Lit. de Debras. 1864.

Ast aparect furmuto an al libro Mexico y su Alrededora, 24 Edición Decate.

Parece ar la misma litografia de Casimiro Cantro que apande en negro con la cindad tomada a ojo de psjacto.

84. 1870.

"Plano tipografico de la costa de Sotavento de Veracruz."-R. Jinvico, 1870. Lit. "La Nacional." Habana.

Mirabal, póg. 145.

85. 1878.

"Plano tipográfico de la H. ciudad de Veracirz." Por 1. P. Gozmin.

Dirección de Cartagrafía, núm. 6699.

86. 1870 .

"Plano de Veracruz. Delineado con el objeto de mostrar la red de cañerias empleada para diatribuir el agra del Janapa en las callea de la ciudad." 1870 . (Se Jcompañan otros dos planos con diversos detalles).

Cartografia, p. 229. núm. 1768.

87. 1895.

"Plano de la ciudad de Veracruz." Por I. P. Guzmín.

Dirección de Cartografie, núm. 6697.

88. 1895.

"Plano de la ciudad de Veracruz", impreso a colores. I. Palacios.

Dixecsion de Cartografía, nóm. 6698.

89. 1899.

"Plano topográfico e bidrográfico de la ciudad y puerta de Vemerez." Autoridad I. P. Guzmán. del Catálogo.

M. S. Original Inatituto Panamericano de Geografia e Historia. Nún. 478

90. 1900.

"Plano del puerto de Veracruz.-Plan of the city and port of Veracruz, Howing new harbar and imrovemento." "Veractaz. Huarado", píg. 98.

Parece ser el plano-proyecto de la Companía Contetructora del puerto, paes muchos de los mueliet que en el figuran no fueron ens- 
truidos: véase el plano levantado en 1907 por la comisión Geográfico-exploradora.

91. 1907.

"Plano topográfico de la ciudad y paerto de Veracruz, formado por la Comisión Geográfico-Exploradora.-Escala de 1:10.000.-1907."

Se encuentra en la carta del Estado de Vetacruz de la misma Comisión. Sa origen está indicado en la siguiente Nota: Para format este plano se ntilizó el levantamiento por el Ing. Ignacio P. Guzmán en 1895 y los datos de las obras del Puerto, con las rectificaciones hechas por el Teniente Coronel de E. M. Luia Salgado en el año de 1907.

92. 1914.

"Plano de la ciudad de Veracruz."

L. P. Guzmán.

En seis bojas. Sin duda el mejor plano moderno.

93.

"Plano manuscrito de la cindad de Veracruz, con sa muralla." (Sin fecha ni firma) .

Soc. Geogr. y Estad. Mesa 1 ajon 8.

Mirabal, pág. 163.

94.

"Mapa-Plano de la Muy Noble y Muy Leal Ciudad de Nueva Veracraz $y$ fuette de Ulúa." M. S. sin fecha ni firma.

Soc. Geog. y Estad. 28 mesa, cajón 12.

Mirabal, pág. 180 .

95.

"Plano de la plaza de Veracruz y San Juan de Ulúa." Sin fecha ni firma.

Soc. de Geog. $\nabla$ Estd. $2^{\text {s }}$ mesa cajón 12.

Mirabal, pág. 180.

96.

"Plano de la ciudad de Veracraz." M. S.

Cartografía, p. 266. núm. 2269.

97.

"Plano de Veracruz." M. S.

Cartografia, p. 266, ntim. 2270.

98.

"Plano de Veracruz y sus abburbios." Lit.

Cartografía, D. 267.

V. Ver. Ilutr., p. 85. ntim. 2271. 
99.

"Plano de la ciudad de Vetacruz con el proyecto de su ampliación." Lit. Cartografia, p. 267, núm. 2272.

100.

"Plano de la Heroica Vexacruz." Impreso.

Cartografia, p. 276, núm. 2273.

101.

"Propecto del puerto de DOCKS en Veracruz por el matino mexicano A. Ortiz Monaterio."

Soc. Geog. y Estad. $2^{8}$ mesa, cajón 12.

Sección de Cartograf" a Instituro Nacional de Geog. e Historia.

Mirabal. pig. 183.

102.

"Plano de la parte principal de la costa y puerto de Veracruz desde la Antigua banta Antón Lizardo."--Obsequio a los austitores de Diario Oficial.

Mirabat, pág. 155.

103.

"Plano de ta ciudad de Veracruz y Castillo de San Juan de Uláa", delineado por don Fernando de Pineda. (Sin fecha). 
Americana. Cartes et Plans. imprimes et manuscrits, relatifs aux deux Ameriques. Librnirie Americanaie et Coloniale. Parfw. S. A.

ANGULo INIguez, Diego. Boutista Antonelli. Madrid, 1942.

"Cartas Instrucciones y Cedvlas de Sv Magestad y fortificaciones echas por el Ingeñero Bavtista Antonelli Ansi en España como en las Indias occidentales con les plantas $y$ dixcrepciones de los pwerto y costas. $Y$ offensa $y$ defensa dellas rencrimismo de algunas placas de africa como en este diecurso se berí. Año de 1608". Está reproducida en las Publicaciones de la Hakluyt Society. Serie II vol. XXXIII. 1908.

Estadistica del Estado Libre y Soberano de Vecactuz.

Cuaderno 19 que comprende los Departamentos de Orizaba y Veracruz y Memoria del Gobierno. Jalapa. Impreso por Blanco $Y$ Aburto, en ta oficina del Gobierno del Estado, 1831. Altura 200 $\mathrm{mm}$. Se bizo siendo gobernador don Sebastikn Camacho.

Bibliografia General del Estado de Veeacruz.

Por Joaquín Diaz Mercado, DAPP. México, 1937. Pág. 387. Tomo $\mathrm{I}$.

El Estado de Veracruz, Llave.

Sa Historia. Agricultura, Comercio e Industria. Publicado bajo la dirección y autorización del Gobierno del Estado por J. R. Southwarth. Octubre de 1900.

Indice de los Mapas.

Cartas, Planos de Puertos, Babias, Fortificaciones de Plazas, Castillos $y$ otras demostraciones de obras proyectadas y ejecutadas en América, que se ballan en el Arcbivo de la Secretaria de Estado $y$ 
del despacho de la Gobernación de Ultramar. Archivo de Indias. Papeles de Simancas. Eatante 145 Cajón 7. Legajo 9.

LERDO DE TEJADA, Miguel M. Apuntes históricos de la heroica ciudad de Vera-Cruz. 3 vols. Merico, 1850.

Relación de Fr. Juan de Avila del Saqueo de Veracruz en 1683.

Mannacrito N9 266 Bis, de la Biblioteca N. de Paris. Col. Gonpil. Aleancía. 1937.

Maps relating to Latin Ametica in books and periodicals.

Compited by A. Cuntis Wilges. Ph. D.-Pan American Union.

Wask. 1933.

Mrrabal Laus to de Cartografia de la Socieded Mexicana de Geografia y Estadfatica, hasta 41 de agato de 1937. núm. 2. Dic. 1937. Ea un catálogo becho por un aficionado, a la buena de Dios. En el Boletín de la Soc. Mex. de Geog. y Estad. Tomo 47.

México y au alrededores. 2* Edición. Deeaén. México, 1864.

Noveno Calondario de Camplido, pera 1844. Arreglado al meridiano de Mtxico. Impreso por el propietario. Calle de los Rebeldes Ntim. 2.

Torres Lanzas. Pedro. Relación dectiptiva de loc mapas, planos, 8. de México y Floridas existentes en el Archiva General de Indies. Sevilla, 1900. 2 vols.

RIVERA CNMBAS, Manuel. Historia antigua y moderna de Jalapa $y$ de las revoluciones del Estado de Vecacruz. 5 vols. Mexico, 1869.

Paso y Troncoso, Francieco. Epistolerio de Nueur Espeña. 16 voltimenes. Mexico. 


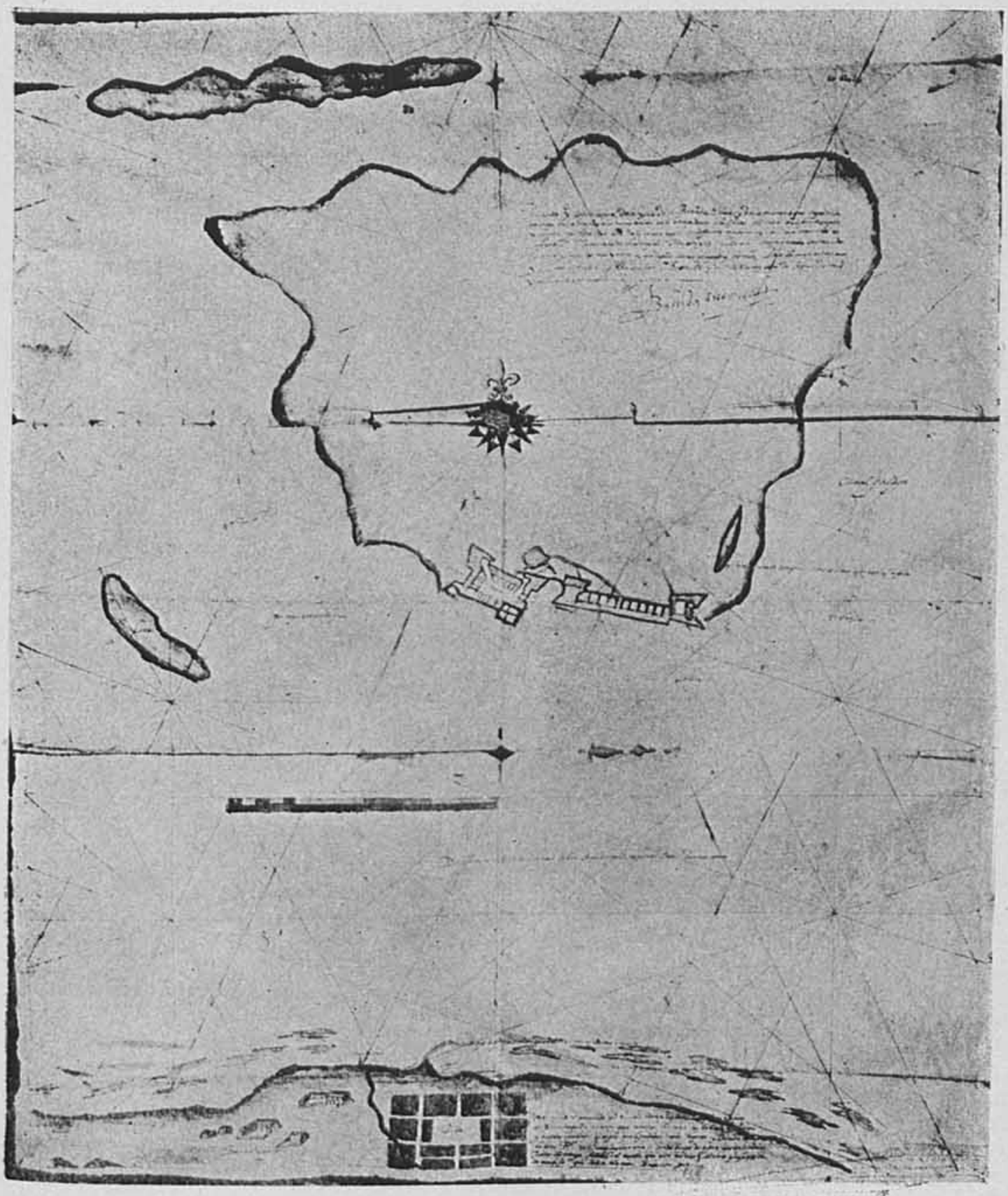

Fig. 1. Traza de Veracruz por Bautista Anconelin-1590 


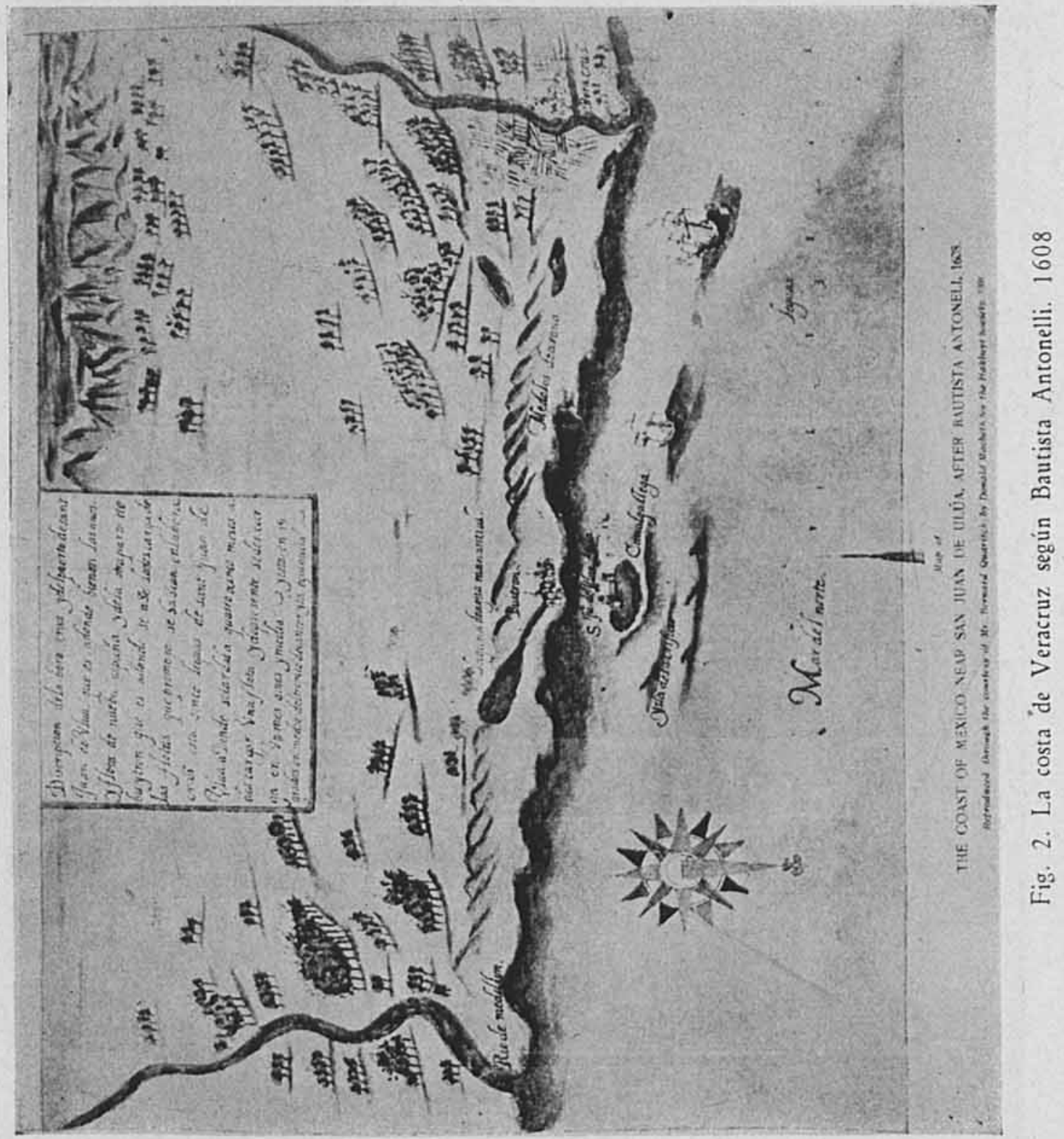




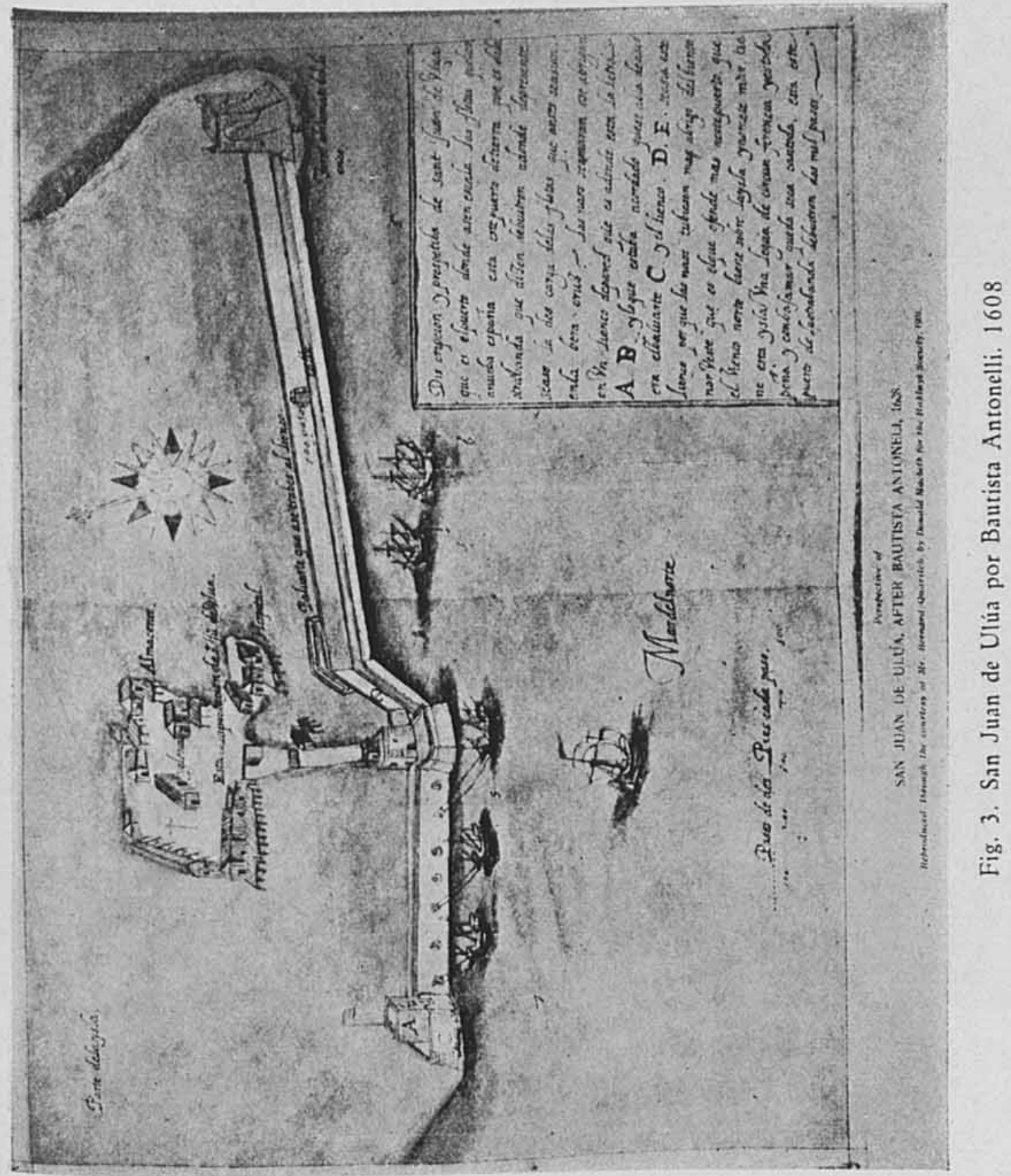


DOI: http://dx.doi.org/10.22201/iie.18703062e.1947.15.439

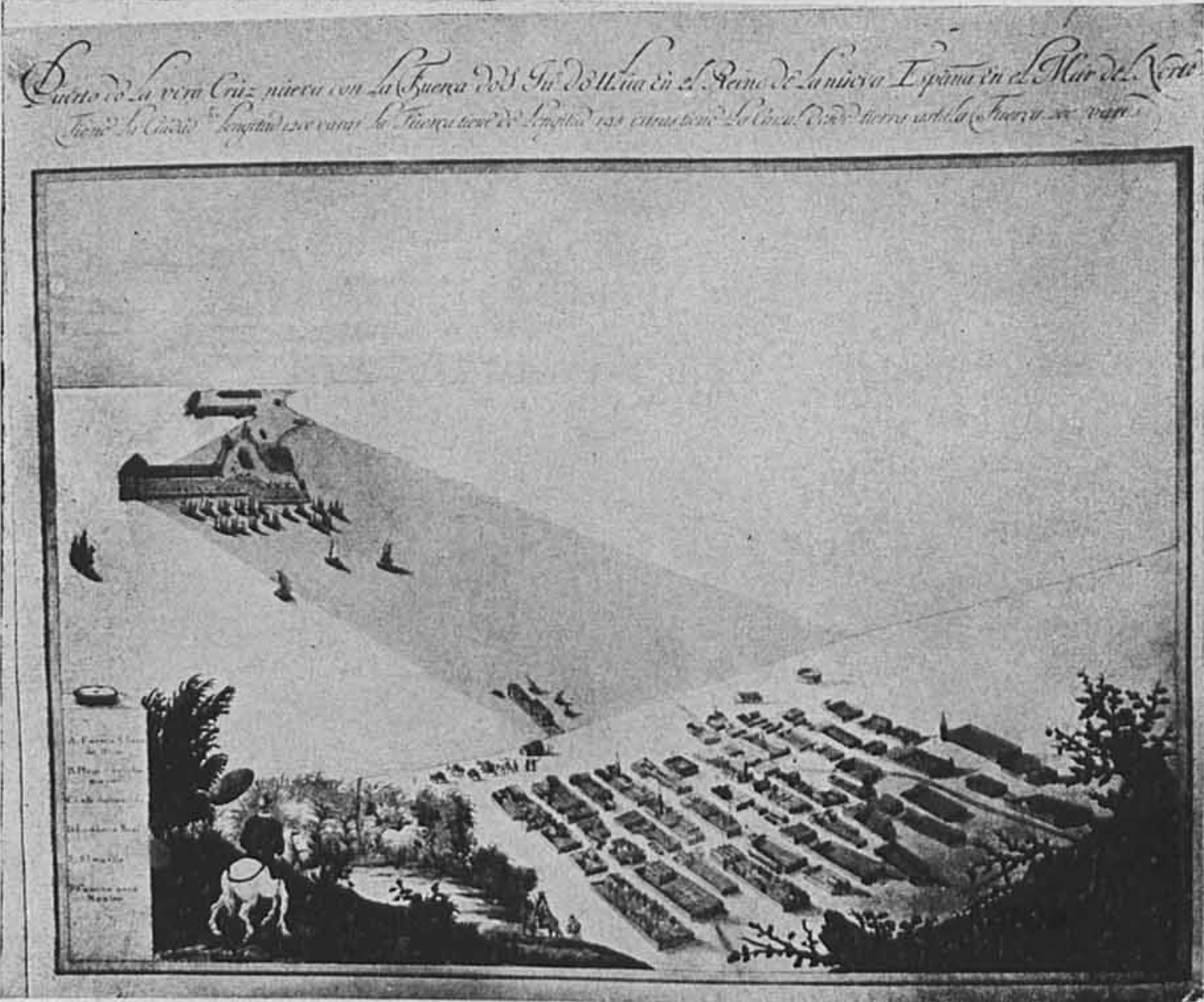

Fig. 4. Perspectiva de Veracruz por Adrián Boot. 1615 


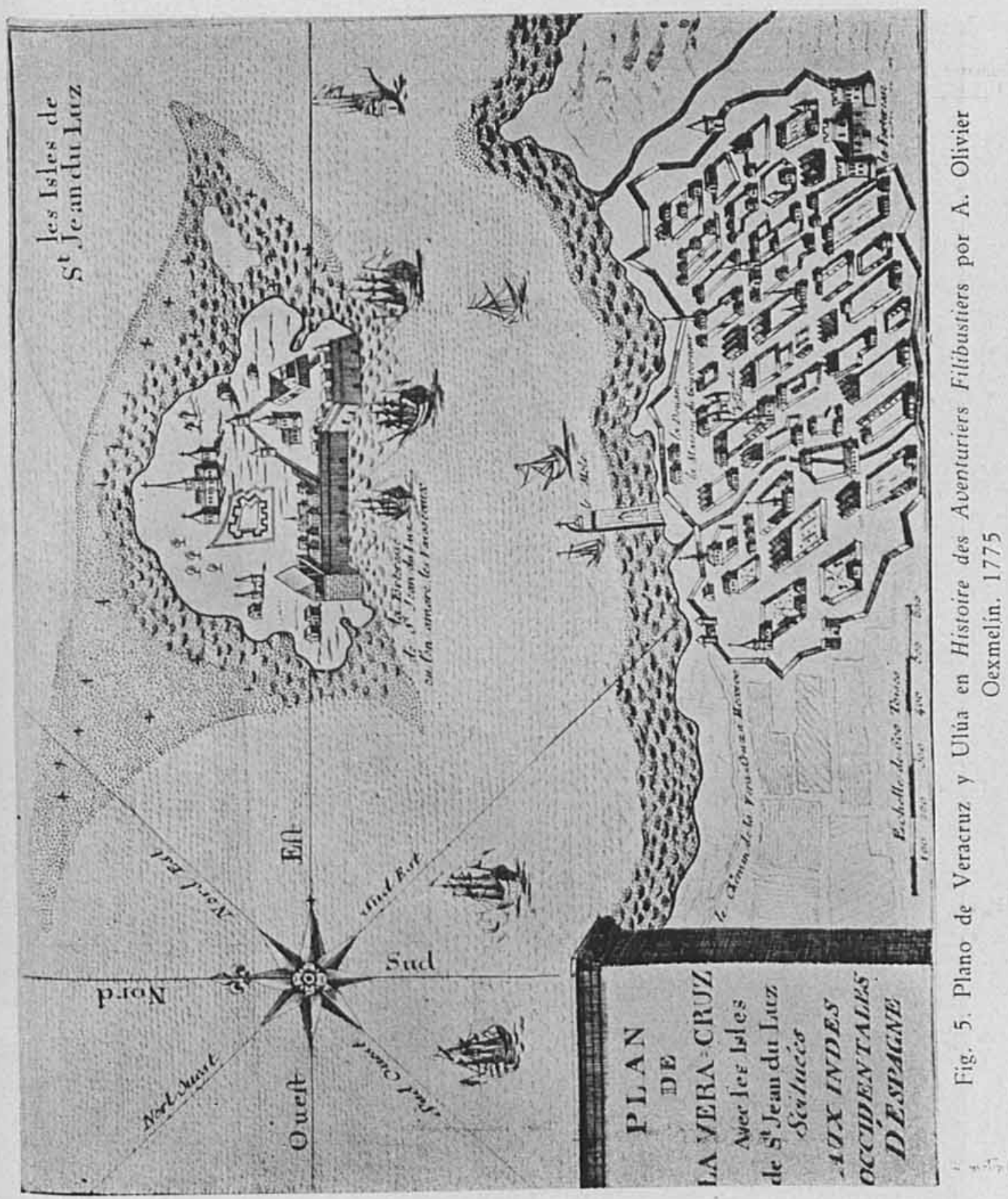




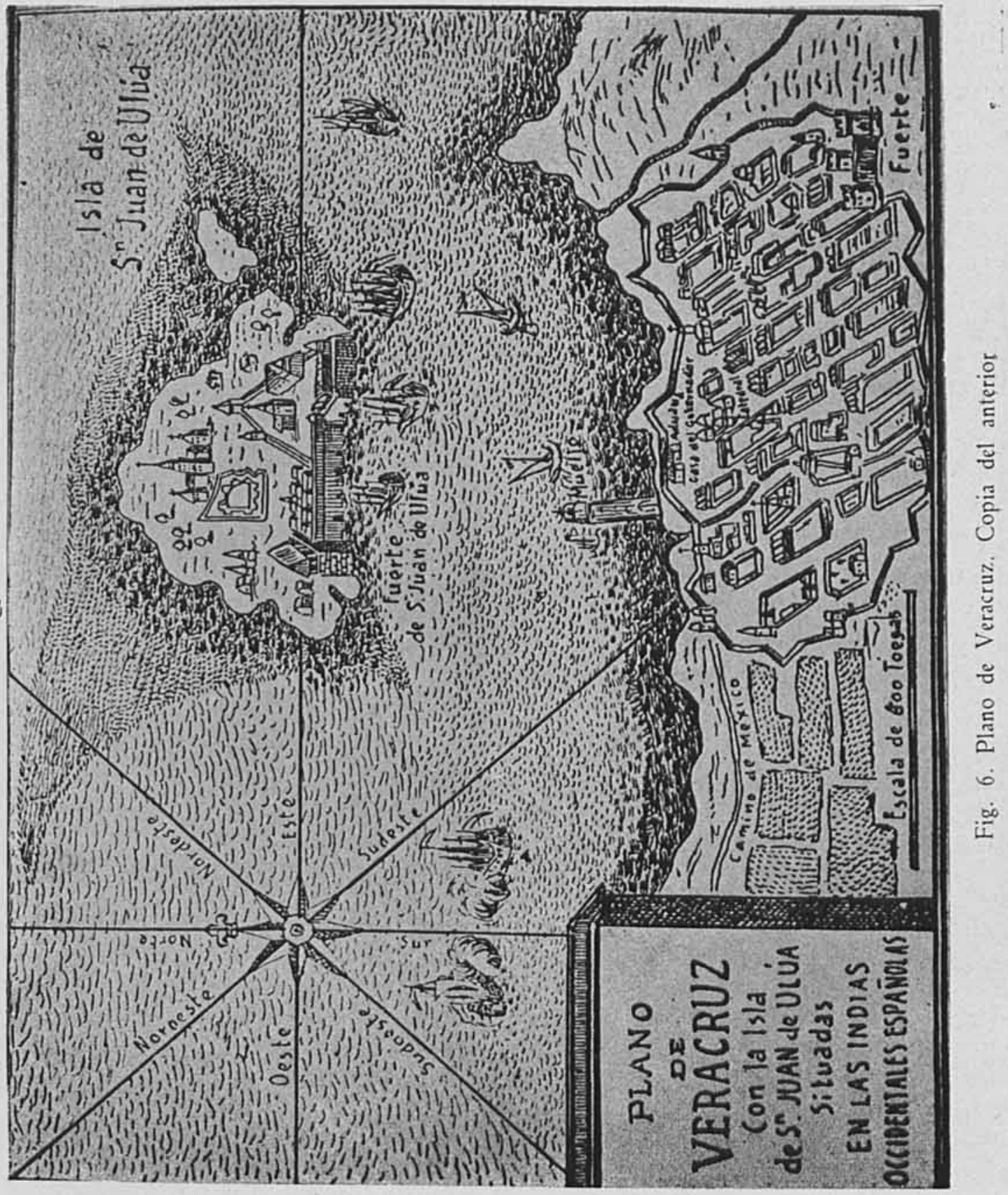




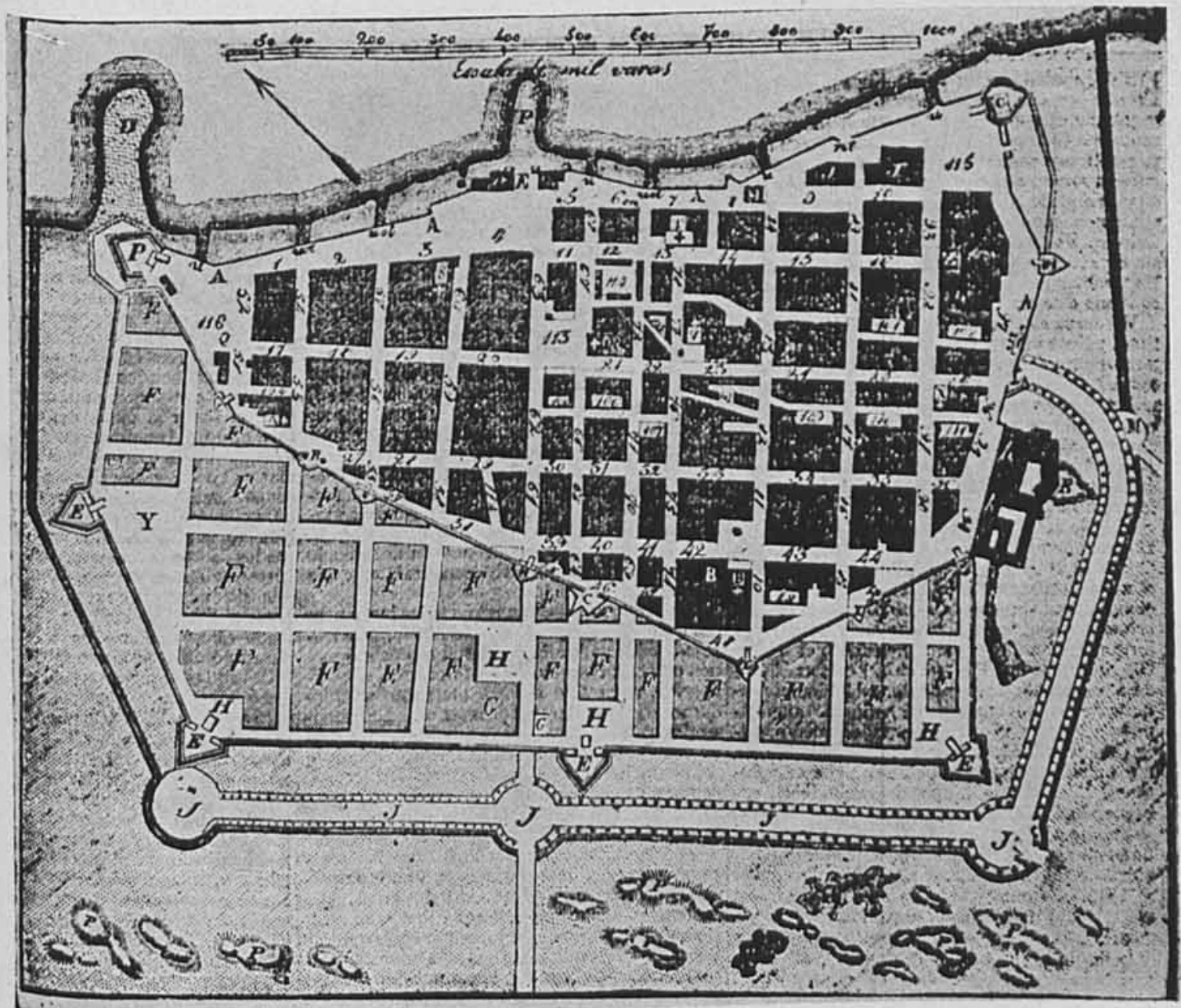

Fig. 7. Proyecto de ampliación de Veracruz por Manuel Agustín Mascaró. 1800 


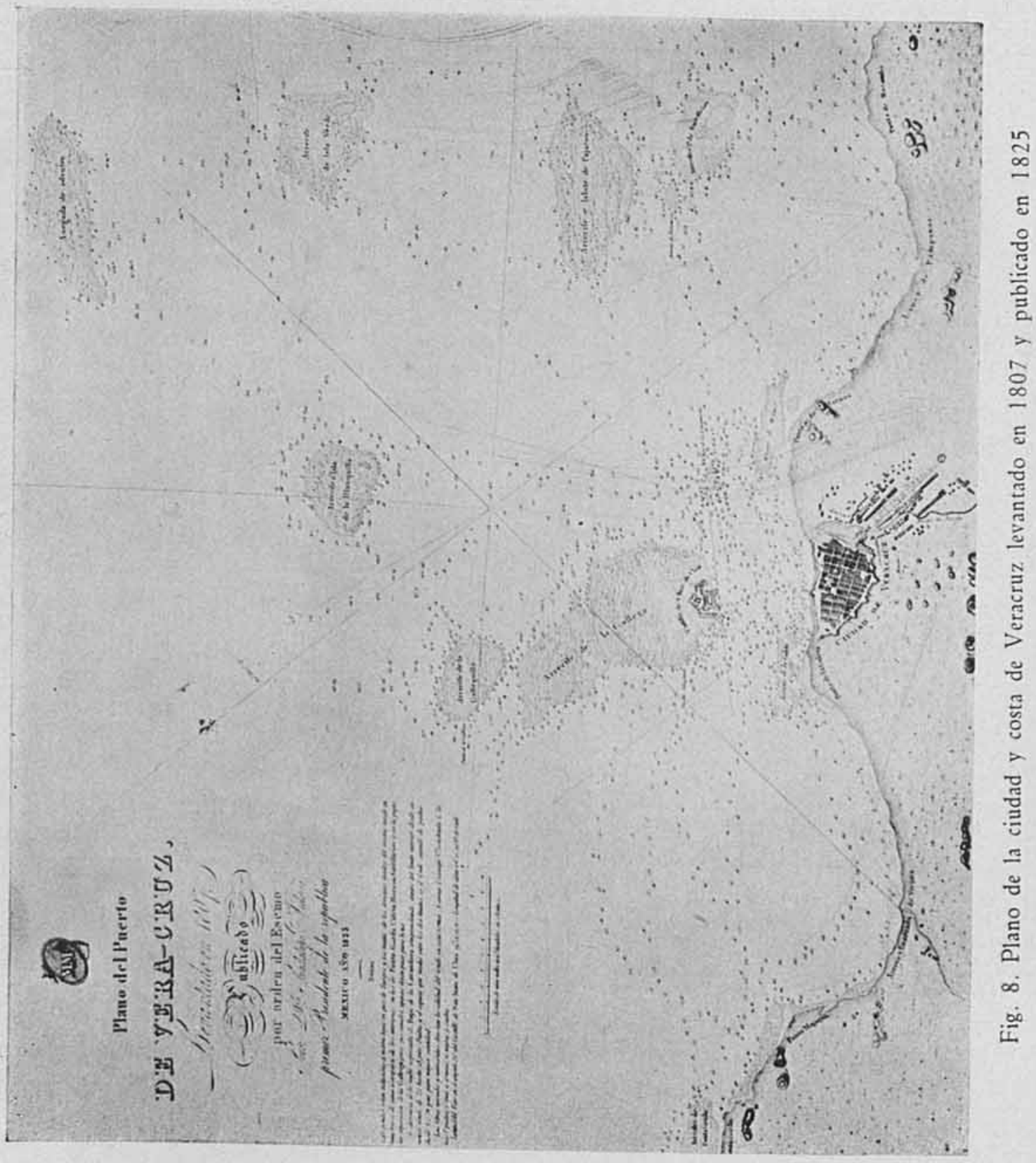




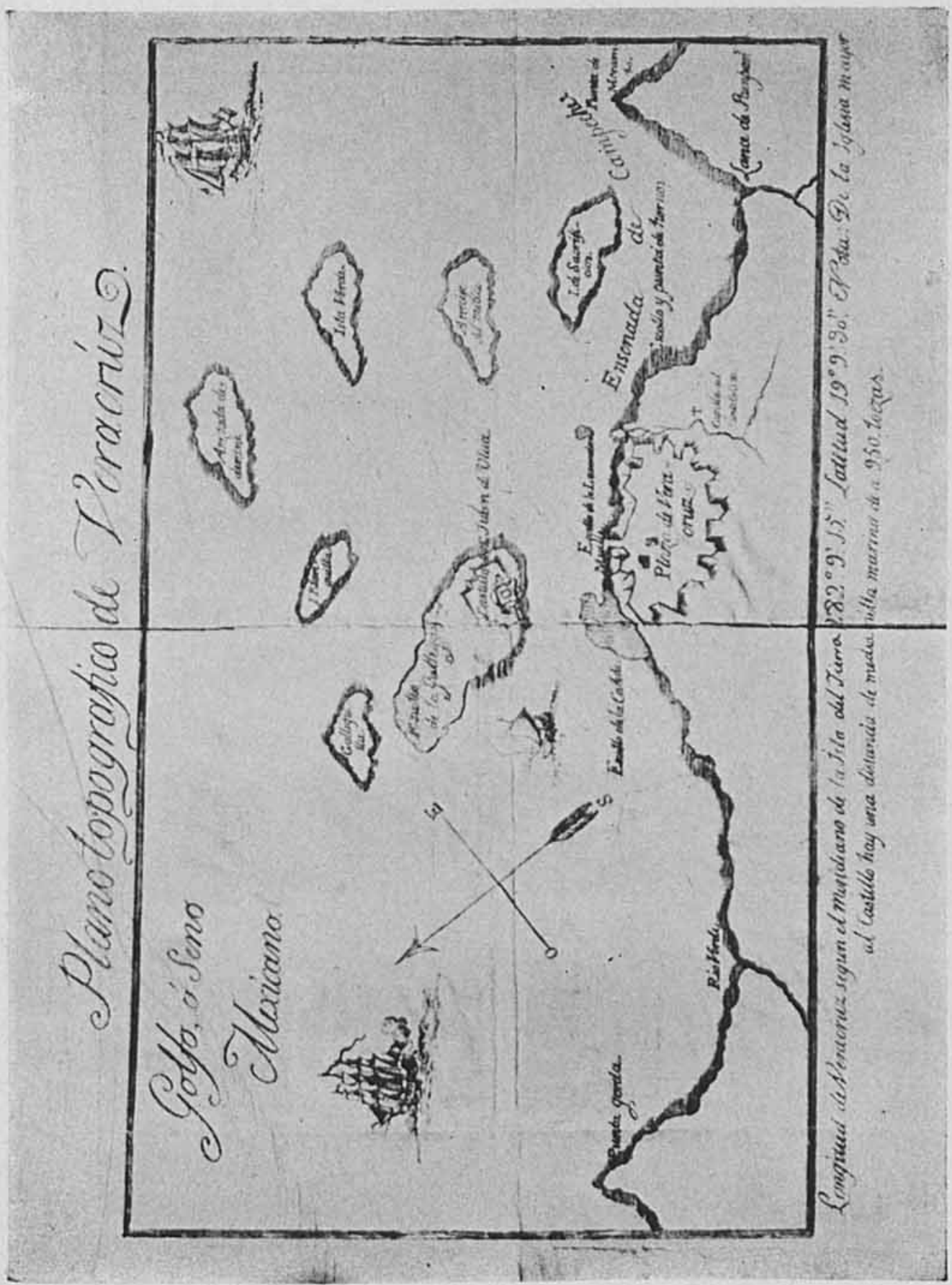

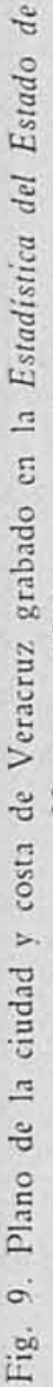


DOI: http://dx.doi.org/10.22201/iie.18703062e.1947.15.439

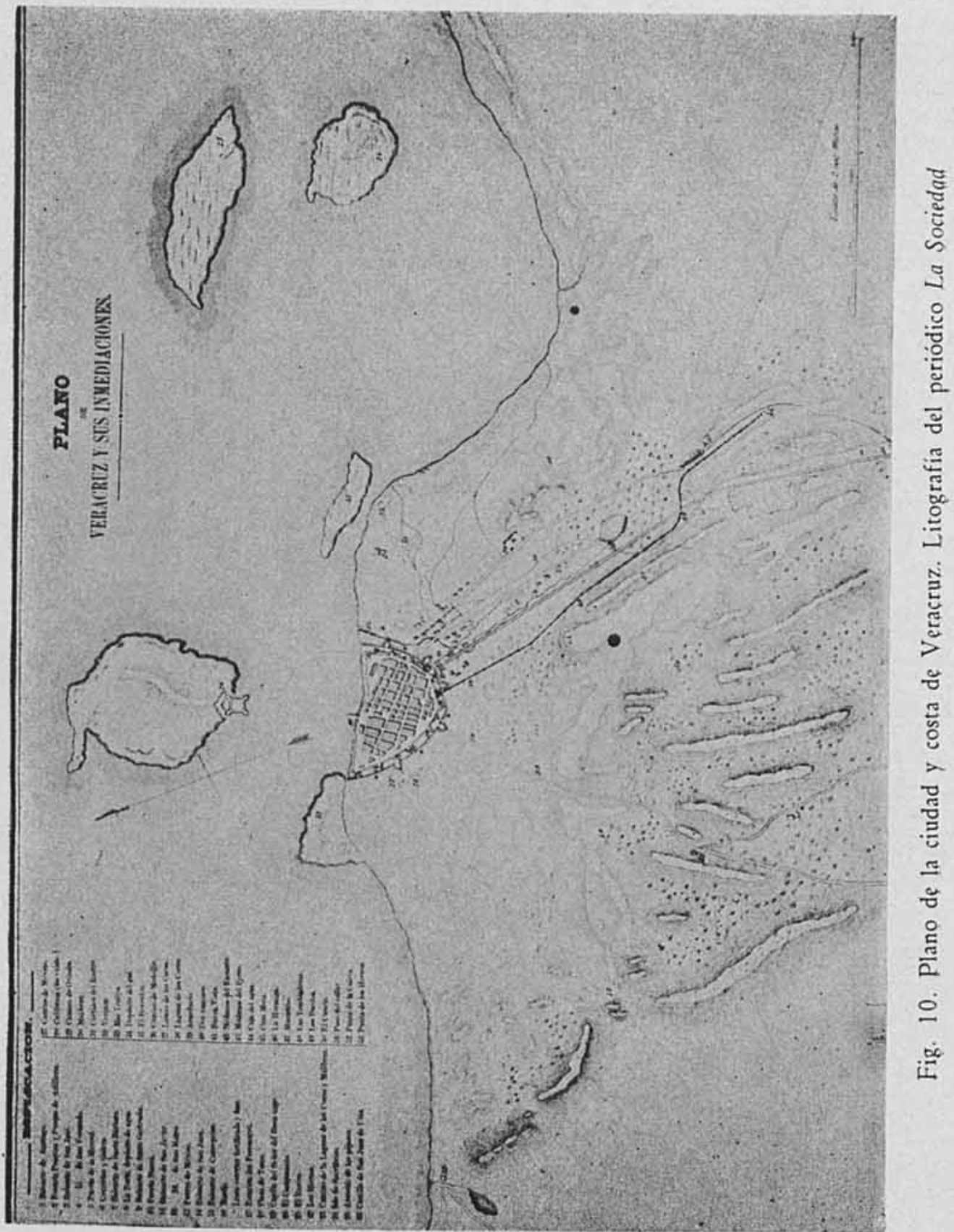




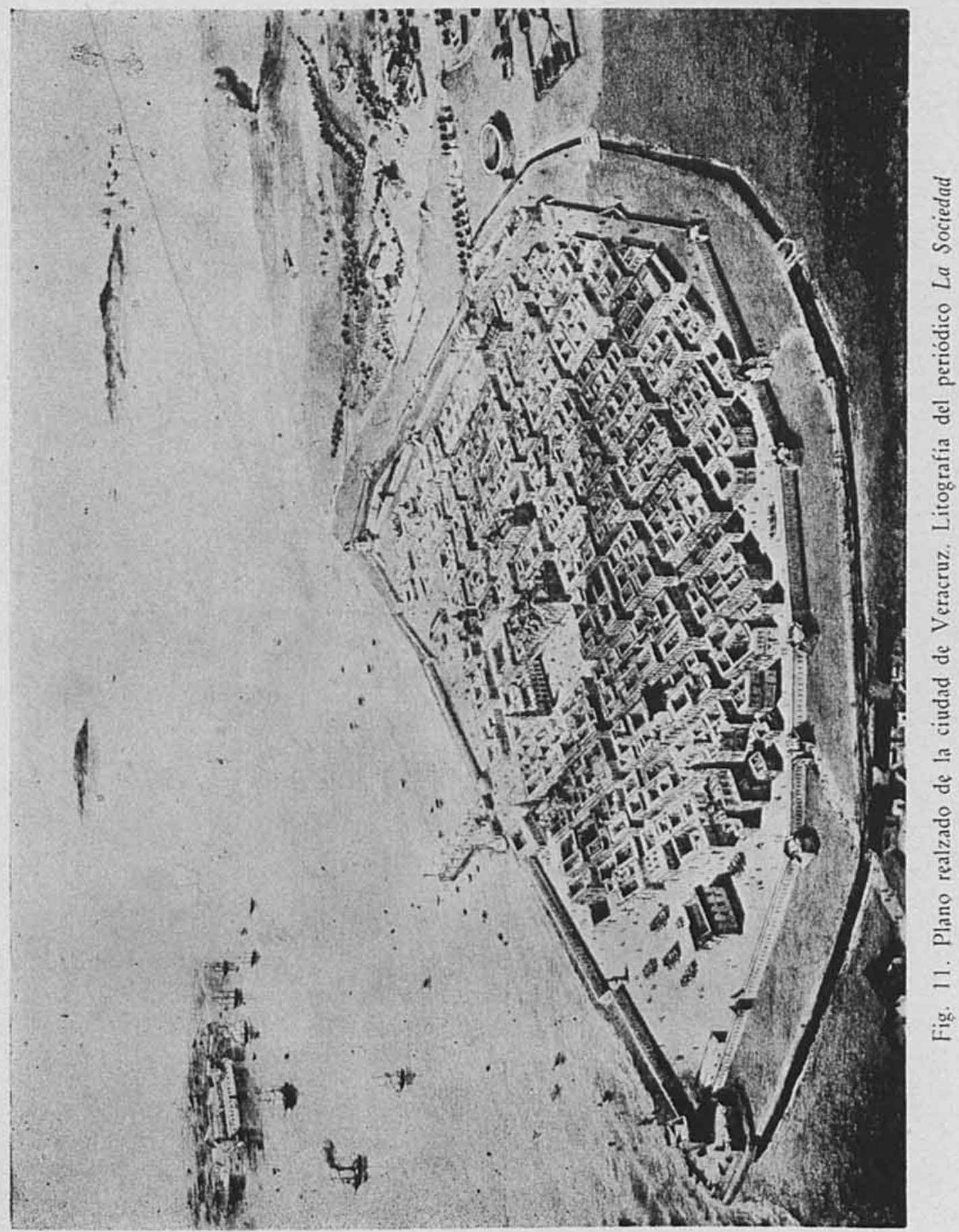


DOI: http://dx.doi.org/10.22201/iie.18703062e.1947.15.439

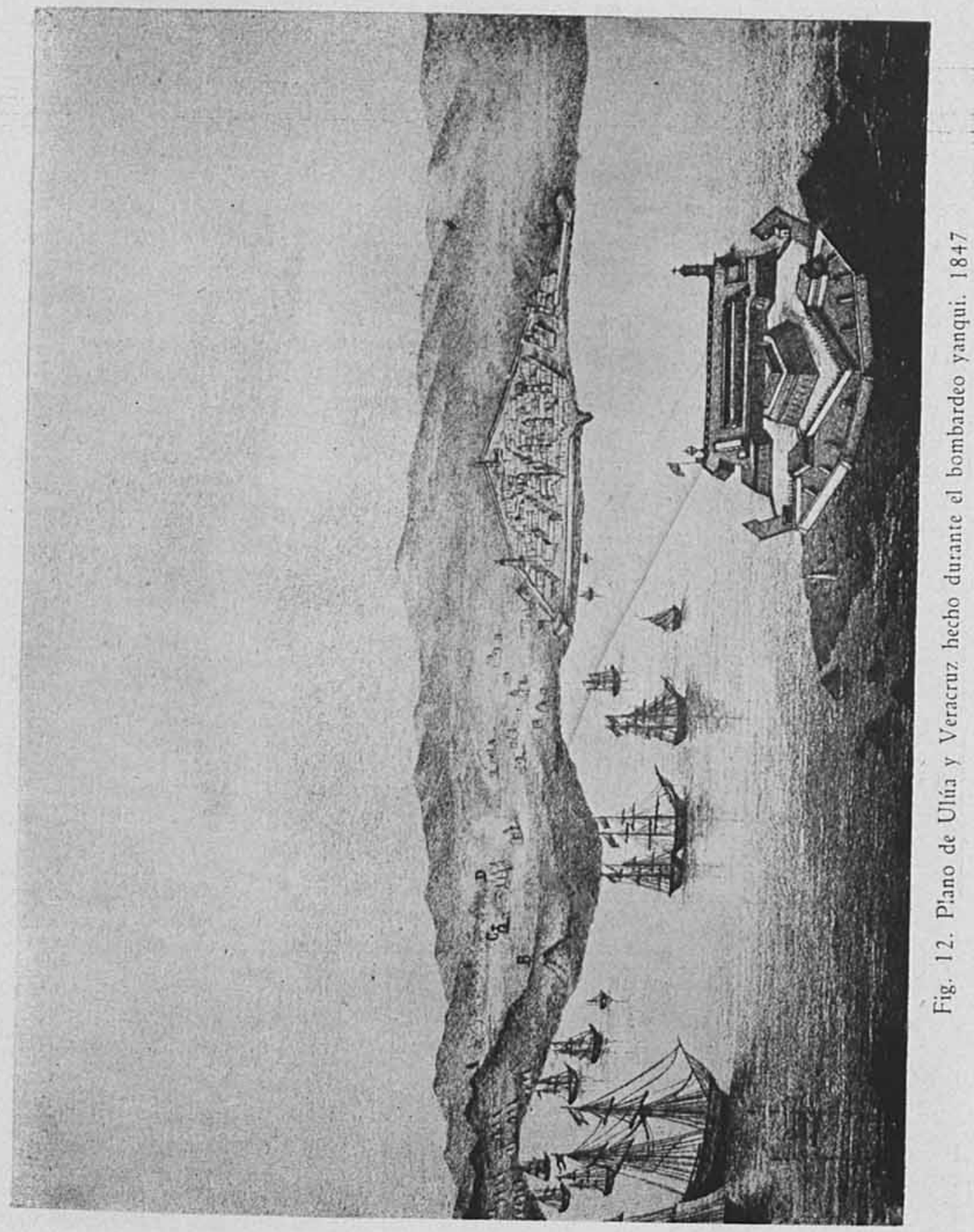




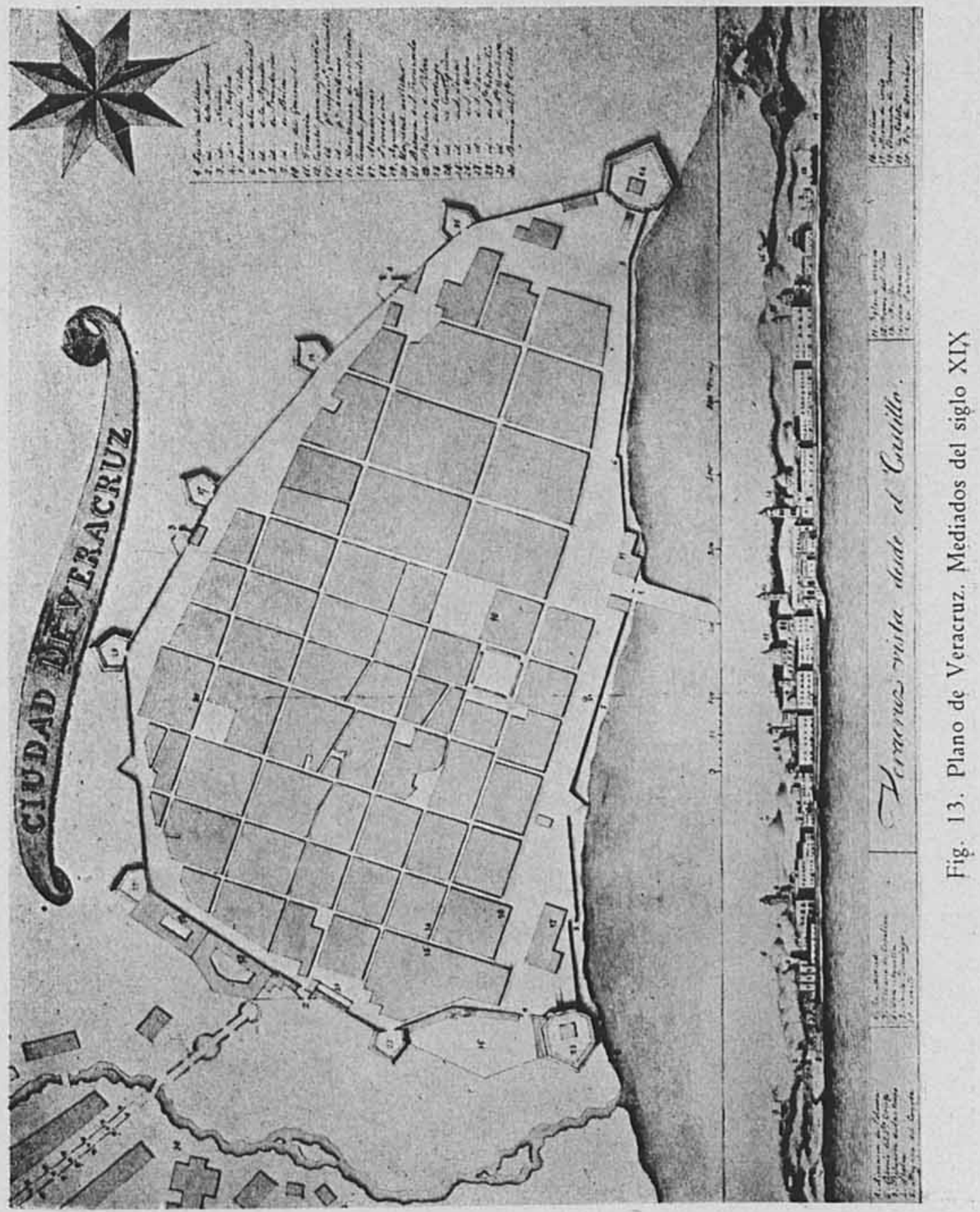




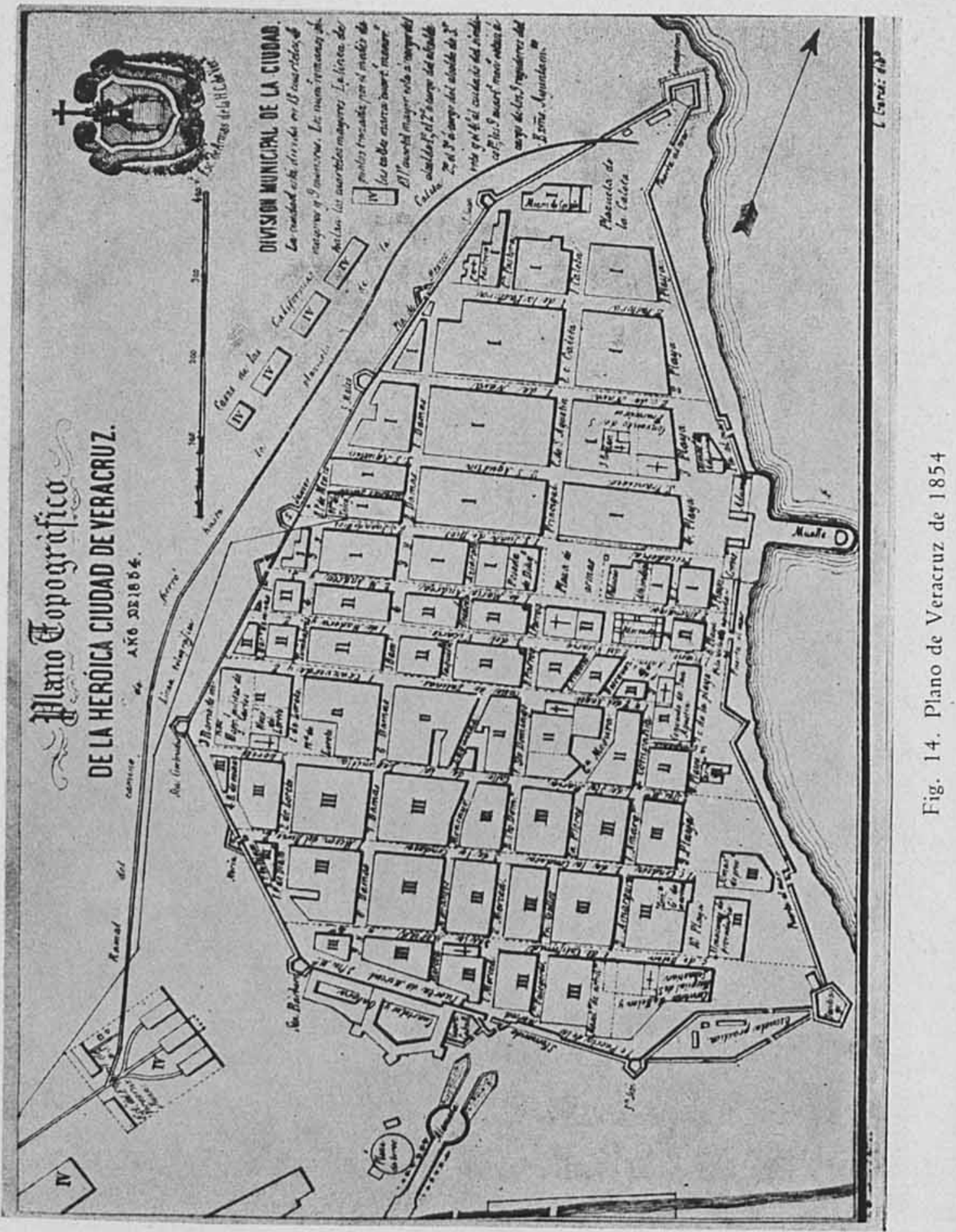




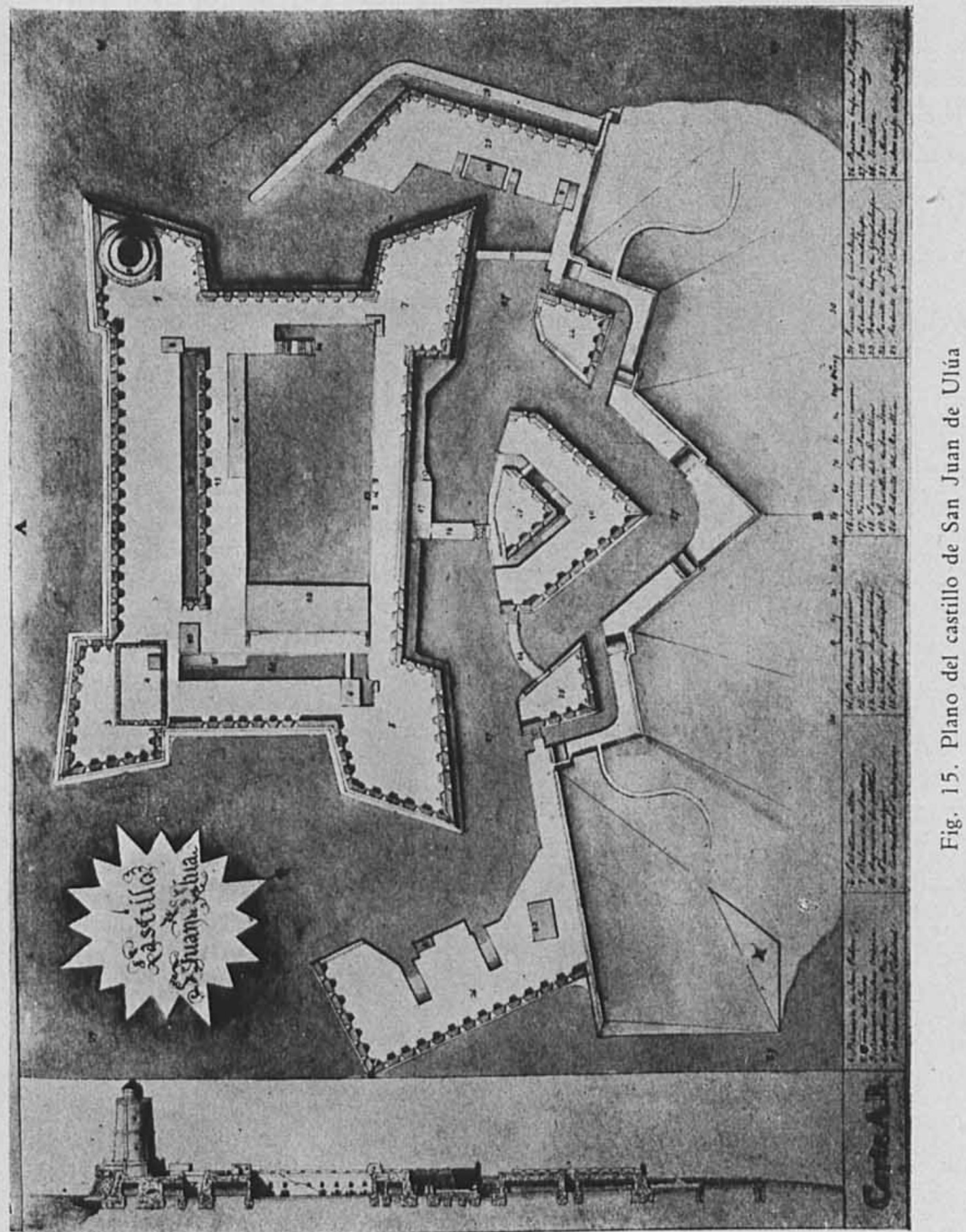

